\title{
Resúmenes de trabajos libres de las 51 Jornadas Médico-Quirúrgicas y ler Congreso Nacional de Influenza. A 10 años de la pandemia de influenza. El camino recorrido
}

\author{
Abstracts of free works of the 51 Medical-Surgical \\ Days and 1st. National Influenza Congress. 10 years \\ after the influenza pandemic. The road traveled
}

\section{TRABAJOS ORALES}

\section{Ventilación mecánica no invasiva (VMNI) en pacientes pediátricos con crisis de asma grave/casi fatal}

Jhonatan Mata-Aranda, Emma García-Colín, José Luis Carrillo-Alduenda, Alejandro Alejandre-García

INER ISMAel Cosío Villegas

Introducción: Una crisis asmática es el empeoramiento de los síntomas de asma que ocasiona modificaciones en la función pulmonar. La gravedad se evalúa con la frecuencia cardíaca (FC), frecuencia respiratoria (FR) y $\mathrm{SaO}_{2}$ (<88\%); FEV1 o (PEF) $<35 \%, \mathrm{PaO}_{2}<60$ $\mathrm{mmHg}, \mathrm{pCO}_{2}>40 \mathrm{mmHg}, \mathrm{pH}<7.35$. Los hospitalizados tienen una mortalidad de $0.4 \%-0.9 \%$, si amerita ventilación mecánica invasiva (VMI) incrementa hasta 10\%. La VMNI mejora la ventilación al descargar los músculos respiratorios fatigados e incrementar la ventilación alveolar, conserva los reflejos protectores de las vías respiratorias, disminuye el autopeep, no requiere sedación y tiene menor tasa de neumonía asociada al ventilador. Objetivo: Dar a conocer los beneficios del uso de la VMNI en pacientes con crisis de asma grave/ casi fatal. Material y métodos: Estudio retrospectivo, descriptivo, corte transversal con un período de marzo 2018-marzo 2019. Las variables continuas se expresan como mediana (mínimo y máximo) y las dicotómicas en frecuencia. Las variables continuas se compararon con pruebas de rangos señalados de Wilcoxon. Programa estadístico utilizado: STATA. Resultados: Los principales factores para una crisis de asma grave/casi fatal es el mal control por un tratamiento inadecuado o por falta de éste. En este estudio se demuestra mejoría clínica y gasométrica posterior a una hora de su inicio, evaluada mediante FC y FR ( $\mathrm{p}<0.00)$, lo cual fue estadísticamente significativa; así como $\mathrm{Ph}$ (p 0.045), $\mathrm{PaO}_{2}$ (0.00), $\mathrm{PaCO}_{2}$ (p 0.028), $\mathrm{HCO}_{3}$ (p 0.016), y $\mathrm{SaO}_{2}$ ( $\mathrm{p}$ 0.007). No se presentaron complicaciones, las presiones utilizadas con rangos mínimos fue bien tolerada por el 100\% de los pacientes y ninguno ameritó VMI. Conclusiones: El uso de VMNI en estos pacientes es una herramienta útil cuando ya se agotaron las medidas convencionales antes de recurrir a VMI.

\section{La proteína del surfactante $D$ como biomarcador pronóstico en infección por el virus influenza $A / H 1 N 1$}

José Alberto Choreño-Parra, ${ }^{*}$ Nora Elemi Regino-Zamarripa, Erika Mariana Hernández-Montiel, ${ }^{\neq}$

Carmen Margarita Hernández-Cárdenas, ${ }^{\ddagger}$ Joaquín Alejandro Zúñiga-Ramos ${ }^{\ddagger}$

*Instituto Politécnico Nacional, México; ‡INER ISMAEL Cosío VILLEGAS

Introducción: $\mathrm{El}$ virus pandémico influenza A/H1N1causa alta mortalidad en individuos con características de riesgo. No obstante, se requieren mejores biomarcadores predictores de mortalidad en pacientes infectados por dicho virus. La proteína del surfactante D (SP-D) participa en la defensa pulmonar y sus niveles séricos aumentan tras la lesión de la membrana alveolocapilar por diferentes causas. Hipótesis: La SP-D es un predictor de mortalidad en infección por el virus influenza A/H1N1. Objetivo: Determinar si la SP-D es un predictor de mortalidad en infección por el virus influenza A/H1N1. Material y métodos: Estudio de cohorte en pacientes con infección por el virus influenza A/H1N1 ingresados a la Unidad de Cuidados Intensivos (UCI). La población de estudio se dividió en sobrevivientes y fallecidos. Se determinaron los niveles séricos de SP-D al ingreso a UCI y al egreso o fallecimiento en ambos grupos. Se compararon curvas de supervivencia de acuerdo con los niveles séricos iniciales de SP-D. Resultados: Se incluyeron 30 pacientes: 24 sobrevivientes y 6 fallecidos (edad media 46 años). Los niveles séricos de SP-D al ingreso a UCI fueron menores en sobrevivientes $(386.1 \pm 217.3 \mathrm{ng} / \mathrm{mL}$ versus $454.9 \pm 156.2 \mathrm{ng} / \mathrm{mL}$, $\mathrm{p}=0.1740$ ). Los pacientes fallecidos mostraron un incremento en los niveles de SP-D al momento de su defunción comparados con las determinaciones finales en sobrevivientes $(1006 \pm 410.1 \mathrm{ng} /$ $\mathrm{mL}$ versus $332.3 \pm 157.3 \mathrm{ng} / \mathrm{mL}, \mathrm{p}<0.0001)$. La supervivencia a 28 días fue del $100 \%$ en pacientes con valores de SP-D < $300 \mathrm{ng} /$ $\mathrm{mL}$ y de $58.36 \%$ en pacientes con valores mayores $(\mathrm{p}=0.0045)$. Conclusiones: La SP-D es un predictor de mortalidad en infección por el virus influenza A/H1N1. 


\section{Niveles de miR126 en pacientes con neumonía grave por virus de influenza pandémica $A / H 1 N 1$}

\author{
Nora Elemi Regino-Zamarripa, \\ Joaquín Alejandro Zúñiga-Ramos, \\ Carmen Margarita Hernández-Cárdenas, \\ Luis Armando Jiménez-Álvarez, Gustavo Ramírez-Martínez, \\ Erika Mariana Hernández-Montiel \\ INER ISMAel Cosío VILLEGaS
}

Introducción: El virus A/H1N1pdm09 infecta y se reproduce en células epiteliales del tracto respiratorio. Su estudio permitirá prevenir y controlar brotes futuros. Los microARNs regulan la expresión genética, son biomarcadores y blancos terapéuticos. La expresión de miR-126 se ha relacionado con la defensa de la infección. Hipótesis: Sí existen diferencias en el perfil de expresión de miR-126, se asociará a sobreproducción de mediadores inflamatorios en pacientes infectados. Material y métodos: Se incluyeron dos grupos de pacientes con neumonía grave hospitalizados en la UCI del INER. G1: 33 pacientes sobrevivientes, G2: 11 pacientes fallecidos. Se obtuvieron dos muestras de sangre venosa, una al ingreso y otra a la extubación o fallecimiento. Se utilizó TRIZol ${ }^{\circledR}$ para obtener ARN, la cuantificación de miR126 con RT-PCR y Luminex para cuantificar citocinas. La edad fue mayor en los sobrevivientes $(\mathrm{p}=0.005)$. Se presentó obesidad en el $100 \%$ de los fallecidos $(\mathrm{p}=0.007)$. Se evaluó SOFA al ingreso y los fallecidos tenían mayor puntuación $(\mathrm{p}=0.023)$. Encontramos diferencias en leucocitos $(p=0.04)$, linfocitos $(p=0.03)$, neutrófilos $(p=0.001)$, plaquetas $(\mathrm{p}<0.0001)$ y creatinina $(\mathrm{p}<0.0001)$. La expresión de miR126 en los sobrevivientes hay una subexpresión al ingreso y, a medida que avanza su estancia, los niveles de expresión aumentan $(\mathrm{p}=0.002)$; los fallecidos ingresan sobreexpresión y disminuyen en su muestra final $(\mathrm{p}=0.007)$. Citocinas: los sobrevivientes muestran mayor producción de IL-6 ( $\mathrm{p}=0.0006)$, los fallecidos tuvieron un aumento en la muestra final $(\mathrm{p}=0.031)$. Producción de IFN $\gamma$ : los sobrevivientes ingresaron con niveles altos $(p=0.004)$, en los fallecidos no hubo modificación en su estancia $(\mathrm{p}=0.063)$. Conclusiones: Los microARNs predicen el desenlace, se relacionan con genes que controlan la respuesta inmune. La subexpresión de miR126 se asocia con un desenlace fatal. Las citocinas reflejan perfiles inflamatorios que determinan el curso clínico. miR126 participan en la regulación de citocinas proinflamatorias, concluyendo que su desregulación lleva a una pobre recuperación y alta mortalidad en el individuo infectado.

\section{Expresión de receptores de quimiocinas y migración celular durante la tuberculosis sensible y farmacorresistente}

Ranferi Ocaña-Guzmán, Norma Téllez-Navarrete, Lucero Ramon-Luing, Iliana Herrera, Marcia Campillo-Navarro, Leslie Chávez-Galán

\section{INER ISMAel Cosío VILlegas}

Introducción: La tuberculosis (TB) multidrogoresistente (MDR-TB) ha incrementado, pacientes con MDR-TB requieren mayor tiempo de recuperación y tratamiento comparado a pacientes con TB sensible (S-TB). El reclutamiento de células inmunes es fundamental para controlar la infección y es regulado por quimiocinas/receptores, se desconoce si los patrones de migración entre MDR- y S-TB cambian. Hipótesis: La capacidad de migración celular esta afectada en MDR-TB. Objetivo: Evaluar fenotipo y capacidad migratoria de células mononucleadas (CMN) de pacientes MDR-TB y S-TB. Material y métodos: CMN de pacientes con TB (15MDR-TB y 11S-TB) se obtuvieron basal, 1, 3, 8 y 16 meses de tratamiento (mtt) en MDR-TB, basal, 1 y 6 mtt en S-TB. Mediante citometría de flujo realizamos caracterización fenotípica y por fluorometría evaluamos migración de CMN. Resultados: La caracterización fenotípica mostró: a) incremento de monocitos (Mo) proinflamatorios CD16+ y MoCD3+CD16-; éstos últimos no clásicos permanecen altos a $16 \mathrm{mtt}$, disminuyen Mo-CCR2+ e incrementan Mo-CCR4. b) linfocitos T (LT) CD4+: disminución de naïve e incremento de memoria central, incremento de dobles positivas CXCR1 y CXCR3. c) LT CD8+ incrementan los de memoria central como efectora, disminuidos LTCD8+ CXCR1+ y CXCR3+, pero incrementados los doble positivos (CXCR1+CXCR3+). MN de MDR- y S-TB tienen incrementada su capacidad de migración y ésta no disminuye con el tratamiento, las CMN de MDR-TB migran preferentemente en respuesta a IP-10 y las de S-TB a CCL-17. S-TB migra predominantemente la subpoblación CD11b+CD3+. Sugiriendo que MDR-y $\mathrm{S}-\mathrm{TB}$ reclutan diferentes poblaciones celulares. Conclusión: Los datos indican que MoCD3+ y MoCD16+ durante MDR-TB favorecen inflamación prolongada. Debido a que en S-TB los MoCD3+ tienen alta capacidad de migración, es probable que favorezcan la resolución temprana de la infección, desconocemos su participación en la formación del granuloma, pero su estudio podría revelar mecanismos que permitan adquirir ventajas terapéuticas en el tratamiento de la tuberculosis.

\section{Calprotectina, un biomarcador que permite distinguir entre tuberculosis latente (TBL) y tuberculosis activa (TBA)}

\author{
Joaquín Zúñiga-Ramos, ${ }^{*}$ José Alberto Choreño-Parra, \\ Alfredo Cruz-Lagunas, * Luis Armando Jiménez-Álvarez, ${ }^{*}$ \\ Gustavo Ramírez-Martínez,* Marcela Muñoz-Torrico* \\ *INER Ismael Cosío Villegas; \\ ‡Instituto Politécnico Nacional, México
}

Introducción: Existe evidencia de que los neutrófilos son la principal población celular infectada por Mycobacterium tuberculosis $(M t b)$ en pulmón y poco se sabe de su función contra $M t b$. Hipótesis: S100A8/A9 es un biomarcador de progresión en tuberculoisis (TB). Objetivo: Estudiar la función de neutrófilos y su principal componente citosólico, la alarmina S100A8/A9 como biomarcador de progresión de TB. Material y métodos: Se obtuvo sangre periférica de 52 pacientes con TBA, 36 contactos domiciliarios, 28 individuos con exposición laboral a $M t b$ y 26 controles. Se aislaron y caracterizaron neutrófilos por citometría de flujo y se analizó el transcriptoma por ARNseq. Se cuantificaron S100A8/A9 y 50 moléculas de inmunidad por luminometría. Analizamos expresión de ARNm de S100A8/A9, CXCL10, CXCL1 y CD11b en neutrófilos pulmonares de ratones C57BL6 infectados con la cepa HN878 de $M t b$. Las diferencias se analizaron con pruebas estadísticas apropiadas. Resultados: Los niveles de ARNm de S100A8/A9 en neutrófilos aumentaron durante la progresión a TBA. Los niveles séricos de S100A8/A9 fueron mayores $(\mathrm{p}<0.05)$ en pacientes con TBA en relación con controles sanos. Observamos un aumento 
significativo en los niveles séricos de S100A8/A9 en sujetos con TBL (contactos intradomiciliarios y exposición laboral a $M t b$ ) que tuvieron una prueba doble positiva PPD+/QFT+, en comparación con controles sanos PPD-/QFT-. También observamos mayores niveles de S100A8/A9 en individuos con TBL dobles positivos PPD+/QFT+ con exposición ocupacional a TB en comparación con individuos con TBL PPD+/QFT- del mismo grupo. En ratones observamos mayor expresión de ARNm en pulmón y niveles séricos altos de S100A8/A9. Los ratones deficientes de S100A8/A9 infectados tuvieron mayor carga bacilar, mayor patología pulmonar y menos infiltrados pulmonares de neutrófilos, menor expresión de CD11b. Conclusión: Este es el primer trabajo que demuestra la importancia de S100A8/A9 como un biomarcador periférico que correlaciona con la progresión de TB.

\section{El material particulado atmosférico urbano induce el incremento de CD206 asociado a miR-24 en macrófagos}

\author{
José Francisco Cruz-Flores, Claudia Carranza-Salazar, \\ Manuel Guadalupe Salgado-Cantú, \\ Stephan Shwander, Martha Torres-Rojas \\ INER ISMAel Cosío VilLegas
}

Introducción: La exposición a material particulado menor a 2.5 micras (PM2.5) está asociada a una mayor morbilidad y mortalidad por enfermedades pulmonares, su inhalación altera la función de los macrófagos alveolares, importantes en la respuesta inmune pulmonar. Los macrófagos pueden desarrollar un perfil proinflamatorio o antiinflamatorio. En este último destaca el incremento de CD206, que está asociado con la expresión de miR-24-3p, miembro de los ARN no codificantes. Hipótesis: La exposición de macrófagos a PM2.5 durante su diferenciación induce un perfil antiinflamatorio. Objetivo: Determinar el efecto de la exposición a PM2.5 en la diferenciación de macrófagos. Método: Se recolectó PM2.5 en Iztapalapa. Se obtuvieron monocitos de paquetes leucocitarios. Éstos se diferenciaron a macrófagos (MDM) en ausencia o presencia de PM2.5 a $5 \mu \mathrm{g} / \mathrm{mL}$ y $10 \mu \mathrm{g} / \mathrm{mL}$ durante seis días. El PM2.5 intracelular se observó por microscopia. Se analizó por citometría de flujo la viabilidad celular y la expresión de CD14, CD33, CD36 y CD206 y la expresión de miR-24-3p por RT-qPCR. Resultados: La exposición a PM2.5 no afectó la viabilidad de los MDM. La expresión de CD14, CD33 y CD36 disminuyó en MDM expuestos a PM2.5 $(5 \mu \mathrm{g} / \mathrm{mL}$ y $10 \mu \mathrm{g} / \mathrm{mL})$. La exposición a $5 \mu \mathrm{g} / \mathrm{mL}$ y $10 \mu \mathrm{g} /$ $\mathrm{mL}$ de PM2.5 incrementó la expresión de CD206 en MDM (p < 0.005). La expresión de miR-24-3p aumentó significativamente en MDM expuestos a $10 \mu \mathrm{g} / \mathrm{mL}$ de PM2.5 (p < 0.0001). Conclusión: La exposición de macrófagos a PM2.5 durante su diferenciación incrementa la expresión de miR-24-3p y CD206, propios de un perfil antiinflamatorio.

\section{Análisis de variantes genéticas en HHIP asociadas a EPOC}

Alejandro Ortega-Martínez, Ramcés Falfán-Valencia, Gloria Pérez-Rubio, Edgar Abarca-Rojano, Alejandra Ramírez-Venegas, Rafael de Jesús Hernández-Zenteno

INER ISMael Cosío VILlegas
Introducción: La EPOC es una enfermedad respiratoria compleja que presenta limitación crónica del flujo de aire e incremento en la respuesta inflamatoria de las vías aéreas. Variantes genéticas en el gen HHIP se han encontrado asociadas a la EPOC en estudios de genoma completo en poblaciones caucásicas. No hay validaciones en poblaciones con contribución ancestral mestiza. Hipótesis: Existen polimorfismos en el gen HHIP asociados al desarrollo de la EPOC en pacientes mexicanos mestizos expuestos a tabaquismo. Objetivo: Identificar la asociación entre polimorfismos en el gen HHIP y la susceptibilidad a EPOC en fumadores. Material y métodos: Se incluyeron 515 participantes clasificados en 2 grupos: 1) pacientes con EPOC secundaria a tabaquismo, (FEP, $\mathrm{n}=202$; 2) fumadores $\sin$ EPOC (FSE, $\mathrm{n}=313$ ) u otra afección respiratoria. Se evaluaron tres polimorfismos tipo SNP (rs13147758, rs13118928 y rs1828591). Se realizó genotipificación por PCR en tiempo real empleando sondas TaqMan. Resultados: En el alelo $\mathrm{G}$ del rs13147758 se identificó una asociación a riesgo $(p=0.0013$, OR $=2.11$, IC95\% $1.35-3.31)$, hallazgo que se comprueba con el modelo recesivo ( $\mathrm{p}=0.0092$ OR 1.65 , IC95\% $(1.13-2.39)$. No se identificaron alelos o genotipos asociados en los otros dos SNPs evaluados. Conclusiones: El rs13147758 se asocia con riesgo aumentado al desarrollo de la EPOC en fumadores en mexicanos mestizos, estos hallazgos constituyen la primera validación poblacional que confirma la asociación a variantes genéticas en HHIP.

\section{Función pulmonar en pacientes con EPOC por humo de leña con y sin síndrome metabólico}

\section{Alejandro Ortega-Martínez, Raúl Eduardo Sánchez-Rojas, Ramcés Falfán-Valencia, Gloria Pérez-Rubio \\ INER ISMAEL Cosío VILLEGAS}

Introducción: La EPOC es una enfermedad prevenible y tratable, que tiene como característica principal la limitación del flujo aéreo. Esta enfermedad tiene como base fisiopatológica la inflamación local a nivel pulmonar; del mismo modo, el síndrome metabólico presenta características propias de una inflamación sistémica que conlleva a diferentes patologías, es importante mencionar que ambas patologías coexisten en un mismo individuo, algo muy común en población mexicana donde la incidencia de ambas patologías es muy elevada. Hipótesis: Existe una disminución de la función pulmonar de pacientes con EPOC secundaria a la exposición al humo por quema de biomasa con síndrome metabólico en comparación de aquellos que sólo presentan la EPOC. Objetivos: Evaluar la función pulmonar de pacientes con la EPOC que presenten el diagnóstico de síndrome metabólico según la clasificación de la ATPIII versus aquellos pacientes con diagnóstico de EPOC. Material y métodos: Se revisaron expedientes del archivo general del INER en pacientes mujeres con EPOC secundaria a la exposición al humo por quema de biomasa con y $\sin \mathrm{SM}$, con $\mathrm{N}=80$ pacientes, de los cuales 22 fueron excluidos, 17 con diagnóstico de EPOC, 25 de EPOC + SM y 16 con SM. Resultados: Se encontraron diferencias estadísticamente significativas en los pacientes con EPOC + SM versus EPOC en las siguientes variables: FVC, FEV1, FEV1post, FVCpost, sístole, IMC, glucosa. Conclusiones: Existe una disminución en la función pulmonar en los pacientes que presentan el diagnóstico de EPOC y SM en comparación de los que sólo presentan EPOC. 
Neumol Cir Torax. 2019; 78 (4): 409-425

\section{Disbiosis en microbioma pulmonar induce polarización de citocinas a Th1 en EPOC por biomasa}

Gloria Pérez-Rubio, Fernando Morales-González, Ramcés Falfán-Valencia, Alejandra Ramírez-Venegas

INER ISMAEL Cosío VILLEGAS

Introducción: La EPOC es una patología multifactorial, cambios en las comunidades bacterianas han sido relacionados con disminución de la función pulmonar, polarización en el perfil de citocinas e incluso exacerbaciones. Los trabajos actuales describen el microbioma de los sujetos con EPOC por tabaquismo; sin embargo, se desconoce en EPOC por humo de biomasa. Hipótesis: Las comunidades bacterianas y el perfil de citocinas en EPOC secundaria a la exposición al humo de biomasa son distintos a los encontrados en EPOC por tabaquismo. Objetivo: Caracterizar el microbioma de pacientes con EPOC secundaria a exposición al humo de biomasa y cuantificar citocinas en sobrenadante de esputo inducido. Material y métodos: Fue recolectado esputo inducido de 37 mujeres con EPOC secundaria a humo de biomasa (EPHL) y de 63 mujeres con exposición (> 150 horas al año) y sin padecimiento de la enfermedad (HLREF). De las células de la muestra de esputo se extrajo ADN para análisis metagenómico. En el sobrenadante de esputo inducido fueron cuantificados un panel de 10 analitos. El análisis de resultados se llevó a cabo mediante SPSS v15.0, GreenGenes y EpiInfo v7.0. Resultados: Mediante análisis metagenómico, el grupo de pacientes EPHL presentó menor abundancia relativa del género Streptococcus $s p$ con respecto al grupo HLREF (20.1\% versus $407 \%$, respectivamente, $p$ $=0.002$ ). En cuanto a las 10 citocinas medidas en el sobrenadante de esputo inducido encontramos diferencias significativas al comparar EPHL versus HLREF en IL-6 (681.9 versus 354.3 pg/mL, p $=0.017)$, IL-4 (159.7 versus $104.3 \mathrm{pg} / \mathrm{mL}, \mathrm{p}=0.034)$ e IL-8 (1297.6 versus $448.6 \mathrm{pg} / \mathrm{mL}, \mathrm{p}=0.009)$. Conclusiones: En pacientes con EPOC secundaria a exposición al humo proveniente de la quema de biomasa, se encuentra disminución de Streptococcus $s p$ y aumento de citocinas que polarizan la respuesta inmunológica al perfil Th1 (IL-6, IL-4 e IL-8), este fenómeno es similar al observado en asma.

\section{Índice de inflamación sistémica e IL-6 se asocian con supervivencia en pacientes con cáncer pulmonar}

\begin{abstract}
Miriam Galicia-Velasco, Lorenzo Islas-Vázquez, Dolores Aguilar-Cázares, Uriel Rumbo-Nava, Renata Báez-Saldaña, José Sullivan López-González
\end{abstract}

\section{INER ISMAEL Cosío VILLEGAS}

Introducción: Se ha reportado que altas concentraciones de IL-6 se asocian con mal pronóstico de los pacientes con cáncer, incluído el cáncer pulmonar. Actualmente, el índice de inflamación inmunológica sistémica (SII), basado en el número absoluto de neutrófilos $(\mathrm{N})$, linfocitos $(\mathrm{L})$ y plaquetas $(\mathrm{P})$, ha sido considerado un indicador pronóstico. Hipótesis: Disminuciones del SII y de la concentración de IL-6 se asociarán con mayor supervivencia en los pacientes con cáncer pulmonar. Objetivos: Determinar el SII y la concentración de IL-6 en pacientes con carcinoma pulmonar bajo tratamiento por quimioterapia convencional. Material y métodos: Se incluyeron pacientes mayores 40 años con diagnóstico confirmado de carcinoma pulmonar primario estadio III y IV con tratamiento de 6 ciclos de quimioterapia convencional. El SII se determinó empleando los valores absolutos de neutrófilos, plaquetas y linfocitos obtenidos de la biometría hemática. La cuantificación de IL-6 se realizó mediante la técnica de ELISA. Se empleó la prueba de Wilcoxon para muestras pareadas, la prueba de correlación de Spearman, así como el método de Kaplan-Meier para asociar el SII con la supervivencia. Se consideró una p > 0.05 como nivel de significancia estadística. Resultados: Los pacientes fueron agrupados de acuerdo con la supervivencia en: supervivencia mayor a 12 meses y menor a 12 meses. Los pacientes con supervivencia menor a 12 meses no mostraron cambios en la concentración de IL-6 ni el SII, mientras que los pacientes con supervivencia mayor a 12 meses mostraron una disminución significativa de la concentración de IL-6, así como del SII transcurridos los 6 ciclos de tratamiento. También existió correlación positiva entre el SII y la concentración de la IL-6. Finalmente, la disminución del SII se asoció con mayor supervivencia de los pacientes. Conclusiones: El SII pueden ser considerado marcador de seguimiento al tratamiento en los pacientes con carcinoma pulmonar

\section{Factores asociados a la recidiva de estenosis subglótica en pacientes tratados en el Departamento de Otorrinolaringologia del Instituto Nacional de Enfermedades Respiratorias de 2006 a 2019}

\author{
Daniela Peralta-Charpenel,* \\ Angélica Margarita Portillo-Vásquez, ${ }^{\ddagger}$ Gabriel Tona-Acedo, ${ }^{\ddagger}$ \\ Armando R. Castorena-Maldonado \\ *Médica Coapa Especialidades; \#INER Ismael Cosío Villegas
}

Introducción: La estenosis subglótica es un padecimiento con baja prevalencia que se relaciona con un alto índice de morbimortalidad, y con una alta recidiva de ésta posterior a tratamiento quirúrgico. Se han reportado que factores asociados a esta recidiva son infecciones, comorbilidades, enfermedades autoinmunes e inmunocompromiso. Sin embargo, no se cuenta con datos del comportamiento de la enfermedad o probables causas de su recidiva en población mexicana. Al contar con estos datos podríamos identificar con mayor facilidad a los paciente en riesgo, dándoles un seguimiento más estrecho que pudiera evitar su intervención de urgencia o una mayor cantidad de días de estancia intrahospitalaria. Por ello, el objetivo del presente estudio es identificar los factores de riesgo relacionados con la recidiva de estenosis subglótica posterior al manejo quirúrgico en los pacientes atendidos en el Departamento de Otorrinolarinogología del INER de 2006 a 2018. Metodología: Se realizó una revisión de expedientes de los sujetos mayores de 18 años con diagnóstico de estenosis subglótica que hayan sido manejados de forma quirúrgica al menos en una ocasión por Otorrinolaringología. Para ello solicitamos al área del Archivo Clínico, buscando los datos correspondientes a género, fecha de apertura de expediente, etiología de la estenosis, enfermedades autoinmunes, fecha de cirugías, técnicas empleadas y fecha de última consulta. Se utilizó log rank para conocer las diferencias entre los diferentes factores que pudieran contribuir a la recidiva y análisis de regresión de Cox para determinar su influencia conjunta, utilizando el programa estadístico Stata 14.1. Resultados: Se ha incluido hasta el momento a 56 sujetos, con edad mediana de 36.73 años, $30.61 \%$ hombres, $17.07 \%$ con tabaquismo positivo, $12.5 \%$, $54.17 \%$ sin comorbilidades. En cuanto a las etiologías $26.53 \%$ fueron idiopáticas, $36.73 \%$ granulomatosis con poliangitis, $20.41 \%$ secundario a intubación orotraqueal, $8.16 \%$ secundario a escleroma respiratorio, $2.04 \%$ a policondritis y $6.12 \%$ a trauma. El síntoma más común fue disnea, 75\%. La técnica más común fue láser y dilataciones, en $48.94 \%$ 
de las cirugías de la primera intervención. En cuanto al análisis de supervivencia, para el tiempo entre la primera y segunda cirugía se encontró que la presencia o no de infecciones de vía aérea superior o antecedente de neumonía o influenza fue signficativa con $\mathrm{p}=0.0092$, y también lo fue la etiología, con $p=0.0009$. Introduciendo dichas variables en la regresión de Cox se obtuvo un HR de 5.46 para etiología traumática y de 3.48 para infecciones. Conclusión: Los factores encontrados como significativos en la regresión de Cox deberían de ser considerados de forma especial durante la evaluación inical para la prevención de recidivas postquirúrgicas.

\section{TRABAJOS EN CARTEL}

\section{La salud emocional influye en la caminata de 6 minutos en pacientes con EPID}

Elizabeth Mariano-Fernández, ${ }^{*}$ Ana Karen Saucedo-Pruneda, Oscar Michael Rodríguez-Barreto, Ana Clauda Contreras-López, ${ }^{\ddagger}$

Luis Enrique Jaramillo-Arellano, ${ }^{\ddagger}$ Ivette Buendía-Roldán ${ }^{\ddagger}$

*Benemérita Universidad Autónoma de Puebla; ‡INER ISMAEL Cosío VILLEGAS

Introducción: La caminata de seis minutos (C6M) tiene un papel clave en evaluación de la capacidad de ejercicio funcional, seguimiento y evaluación pronóstica de pacientes con enfermedades pulmonares intersticiales (EPID), el índice GAP se utiliza también para el pronóstico de estos pacientes. Por otro lado, el diagnóstico de EPID reduce la calidad de vida relacionada con la salud (CVRS) al presentar diferentes grados de depresión o ansiedad. Objetivo: Evaluar si el índice de masa corporal, GAP y la salud emocional influyen en pacientes que tienen una caminata anormal. Hipótesis: Se relacionarán de manera directa los metros caminados con el estado de salud emocional y el índice GAP en pacientes con EPID. Materiales y métodos: Estudio transversal, descriptivo, observacional, período junio-julio 2019. Pacientes con EPID fueron evaluados mediante espirometría, prueba de difusión de monóxido de carbono, C6M. La CVRS mediante el Cuestionario Respiratorio de St.George (SGRQ) y Escala Hospitalaria de Ansiedad y Depresión (HADS). Resultados: Evaluamos 26 pacientes de la cohorte de InMujeres-EPID y FPI del INER, género femenino 88\% ( $\mathrm{n}=23)$, de los cuales $73 \%(\mathrm{n}$ = 19) concluyeron la C6M, el 30\% ( $n=8)$ no la concluyó. La causa principal para la detención de la prueba fue desaturación de oxígeno $<80 \%$ (78 \pm 7 ), comparado a $88 \pm 5 \mathrm{p}=0.0002$ de pacientes que sí concluyeron la caminata. La media en metros: $173 \pm 67 \mathrm{p}=0.00003$. Los pacientes que no concluyeron la caminata mostraron una tendencia a tener ansiedad $p=0.07$. No hubo diferencias en el IMC y GAP. Conclusiones: Pacientes con EPID no mostraron diferencias en mecánica pulmonar, IMC, GAP, pero sí una relación con la escala de ansiedad lo que genera un interés creciente en desarrollar terapias para mejorar rendimiento al ejercicio y estado emocional del paciente.

\section{Letalidad del virus de la influenza en el estado de Aguascalientes, temporada 2018-2019}

Nidia Rodríguez-Plascencia,*

Víctor Rafael Molina-Hernández ${ }^{\ddagger}$

*INER Ismael Cosío Villegas; \#InStituto de Servicios de Salud del Estado de Aguascalientes
Introducción: En Aguascalientes se confirmaron 286 casos de influenza, de los cuales 20 tuvieron como desenlace la defunción, 11 hombres y nueve mujeres, con una razón H:M de 1:0.8. Objetivo: Describir los serotipos de virus de influenza y su letalidad en la temporada 2018-2019 en relación con los casos inmunizados. Material y métodos: Estudio descriptivo, ecológico, observacional, retrospectivo. Se realiza análisis de letalidad por virus de influenza en pacientes inmunizados, no inmunizados y en los que se ignoraba si habían sido inmunizado, así como letalidad en general. Resultados: Virus AH1N1 196 casos, fallecieron 18 pacientes, letalidad de 9.2 por cada 100 casos. La letalidad en el grupo de pacientes vacunados fue de 4.8 por cada 100 casos, a diferencia del no inmunizado que fue de 8.4 defunciones por cada 100 casos y en los que se ignoraba inmunización fue de 37.5 por cada 100 casos. Virus AH3N3 71 casos, en Aguascalientes no hubo defunciones. Virus B 17 casos, hubo dos defunciones, con letalidad de 11.8 defunciones por cada 100 casos. Los dos casos fueron en pacientes no inmunizados, representando una letalidad para este grupo de 16.7 por cada 100 casos. Influenza A: dos casos sin reportarse defunción. Conclusiones: De manera general, la letalidad del virus de la influenza en Aguascalientes fue de siete defunciones por cada 100 casos, a diferencia de nivel federal que fue de 11.2 por cada 100 casos. De las 20 defunciones, uno fue en paciente inmunizado, 16 en pacientes no inmunizados y tres se ignora.

\section{Producción de MMP-7 y MMP-12 en pacientes con infección por el virus de influenza A/H1N1}

Gustavo Ramírez-Martínez, Nora Elemi Regino-Zamarripa, Eduardo Marquez-García, Luis Armando Jiménez-Álvarez, Alfredo Cruz-Lagunas, Joaquín Zúñiga-Ramos

\section{INER ISMaEL Cosío VILlegas}

Introducción: La respuesta inflamatoria temprana a la infección por el virus de influenza contribuye a la enfermedad pulmonar grave y representa un grave problema de salud pública. Durante la infección se da una respuesta inmune exacerbada, caracterizada por una sobre producción de citocinas proinflamatorias y algunos factores de crecimiento que contribuyen al desarrollo de neumonía grave, lo cual puede conferir un elevado riesgo de desenlaces fatales. Se ha demostrado que las metaloproteasas de matriz (MMPs), enzimas remodeladoras de matriz extracelular participan en el procesamiento de proteínas que regulan las respuestas tanto inflamatoria como de reparación tisular. En modelos animales se ha observado que la deficiencia en la expresión de MMPs como MMP-9 tiene un efecto protector contra una infección severa por el virus de influenza. Frente a la infección viral se ha reportado también actividad antiviral de MMPs a través de la regulación de interferones alfa. Hipótesis: La expresión de MMPs en pacientes con influenza A/H1N1 se encuentra incrementada. Objetivos: Evaluar la producción de MMPs en donadores sanos y pacientes con influenza. Material y métodos: Mediante la tecnología Luminex se determinó la producción de MMPs en suero de 15 donadores sanos y 24 pacientes con influenza al momento de ingresar a la Unidad de Terapia Intensiva del INER y al ser dados de alta. Se utilizaron pruebas de estadística no paramétricas; $p<0.05$ se consideró estadísticamente significativa. Resultados: En comparación con donadores sanos, se observa un incremento significativo en la producción de MMP-7 y MMP-12 en pacientes con neumonía 
Neumol Cir Torax. 2019; 78 (4): 409-425

asociada a la infección por el virus de influenza A/H1N1, tanto al momento de ingresar a la Unidad de Terapia Intensiva como al ser dados de alta. Conclusiones: La expresión de MMPs en pacientes con influenza pueden contribuir a la resolución de la infección y evitar así un desenlace fatal.

\section{Grado 3-4 de biopsia de glándula salival no es exclusiva de EPID secundaria a Sjögren}

Pablo Cerda-Flores, ${ }^{*}$ Ana Claudia López-Contreras, ${ }^{\neq}$

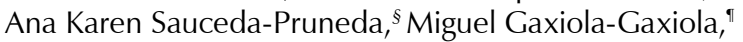
Ivette Buendía-Roldán"

*Universidad Michoana de San Nicolás de Hidalgo; fUniversidad Veracruzana; §UNAM; IINER Ismael Cosío VILlegas

Introducción: La biopsia de glándula salival menor (BGSM) forma parte del diagnóstico del síndrome de Sjögren (SS) y es un estudio que se realiza en el algoritmo diagnóstico de EPID. De acuerdo con la clasificación de Chisholm y Mason, un grado 3 (infiltración linfocítica focal $>50$ células) o grado 4 ( $>1$ foco de infiltración linfocítica) en la BGSM es compatible con los criterios de clasificación de la EULAR/ACR para SS, pero para otras EPID secundarias a enfermedades autoinmunes no se ha evaluado. Hipótesis: Existen otras EPIDs secundarias diferentes a SS que cursan con un grado 3 o grado 4 en el estadiaje histológico de la BGSM. Objetivos. Determinar en qué otras EPIDs secundarias además de SS existe infiltración focal linfocítica en la BGSM. Material y métodos: Se evaluaron los reportes del Departamento de Morfología del INER con estadios 3-4 en la biopsia de glándula salival. Estudio retrospectivo, transversal y observacional, del período 2010 al 2019. Resultados: Se identificaron 121 reportes de pacientes con EPID y grado 3 o 4 en la BGSM, 45\% tenían SS, 22\% esclerosis sistémica (ES), $9 \%$ artritis reumatoide (AR), $7 \%$ neumonía intersticial no específica, $6 \%$ lupus eritematoso sistémico (LES), $6 \%$ neumonitis por hipersensibilidad, $2 \%$ síndrome antisintetasa y $2 \%$ vasculitis. Se observó que, en general, los pacientes que tenían mayor afectación glandular (grado 4) eran más jóvenes $(\mathrm{p}=0.04)$. Esto fue igual para el subgrupo de esclerosis sistémica $(\mathrm{p}=0.03)$. En el subgrupo de SS se observó que las mujeres presentan más a menudo afectación grado $4(\mathrm{p}=0.02)$. Conclusiones: La BGSM puede verse afectada de manera importante en EPIDs secundarias diferentes a SS, principalmente ES, AR y LES. No existe relación entre el grado en la BGSM y las PFRs.

\section{Expresión de miRNAs en biopsias de pacientes con fibrosis pulmonar secundaria a enfermedades reumáticas}

Alfonso Rafael Salgado-Aguayo, ${ }^{*}$

Daniel Paz-Gómez,* Miguel Gaxiola-Gaxiola,

Sandra Romero-Córdoba, ${ }^{\ddagger}$ Alfredo Hidalgo-Miranda, María del Carmen Navarro-González*

*INER Ismael Cosío Villegas; ‡Instituto Nacional de Medicina Genómica

Antecedentes: Pacientes con enfermedad reumática generalizada (ERG) tienen una prevalencia importante de enfermedad pulmonar intersticial difusa (EPID, un 80\%). La EPID puede ser la manifestación inicial de una ERG, lo que dificulta el diagnóstico de estas enfermedades y subraya la importancia de contar con nuevas herramientas diagnósticas. Los microRNA se expresan de forma diferencial en ciertos padecimientos: miR-21 se encuentra incrementado en FPI, mientras que tejido sinovial y linfocitos $\mathrm{T}$ de pacientes con AR tienen modificaciones en la expresión de miR-155. Los miRNAs se conservan en tejidos preservados en parafina, es decir, en estas muestras podrían detectarse patrones de expresión de miRNAs, lo cual abre la posibilidad de obtener nuevas herramientas diagnósticas y de entender mejor las EPID-ERG. Objetivo: Analizar patrones de expresión de microRNAs en biopsias pulmonares de pacientes con EPID-ERG. Material y métodos: Se estudiaron biopsias pulmonares en parafina de pacientes con EPID: FPI $(n=8)$, AA $(n=$ $8)$, AR $(n=7)$, SS $(n=11)$ y ESP $(n=7)$. Se extrajo RNA total de cada biopsia, se purificó, se retrotranscribieron los miRNAs y se preamplificaron. Este cDNA se amplificó con el sistema TLDA (Life Technologies). Los datos de CT normalizados se compararon entre grupos para identificar patrones de expresión. Resultados: Un número importante de miRNAs tuvo expresión diferencial significativa entre los distintos grupos: entre AR y ESP o entre SS y ESP hay alrededor de 20 miRNAs expresados diferencialmente, mientras que entre AR y SS únicamente un miRNA parece tener expresión diferencial significativa. El análisis ontológico de los mRNA regulados por estos miRNAs muestra posibles alteraciones en vías importantes para la respuesta inmune y para la homeostasis del epitelio pulmonar. Conclusión: Los patrones de expresión de miRNAs descritos pueden tener utilidad en el diagnóstico de las EPID-ERG, podrían ayudar a aclarar la fisiopatología de dichas enfermedades y quizá indicar blancos terapéuticos novedosos.

\section{Aplicación del índice de comorbilidades de Charlson en pacientes con enfermedad pulmonar intersticial difusa}

Itzel Abigail Vargas-Pérez,* Ivette Buendía-Roldán," Oscar Rodríguez-Barreto, ${ }^{\ddagger}$ Ana Karem Sauceda-Pruneda ${ }^{\ddagger}$

*Universidad Autónoma de Sinaloa; ‡INER ISMAEL Cosío VILLEGAS

Introducción: El índice de Charlson es un sistema de evaluación de esperanza de vida a 10 años, tomando en cuenta las comorbilidades del paciente y su edad. La base del índice de Charlson son las patologías crónicas, cada comorbilidad tiene un puntaje establecido, da como resultado el riesgo relativo de mortalidad. Actualmente no hay estudios en enfermedades pulmonares intersticiales difusas (EPID) que usen el sistema de índice de Charlson en pacientes mexicanos. Hipótesis: Los pacientes con FPI tienen una mayor riesgo de mortalidad que el resto de las EPID. Objetivo: Medir el índice de Charlson en pacientes con EPID e identificar la EPID con mayor índice de mortalidad. Material y métodos: Estudio descriptivo, observacional y transversal, realizado en el INER en el período junio-julio 2019. Se revisaron expedientes de pacientes con EPID con seguimiento en el Laboratorio de Investigación Traslacional, se evaluaron sus pruebas de función respiratoria al ingreso y se aplicaron los 19 ítms del índice de Charlson, que se interpretó como ausencia de comorbilidad de 0-1 punto, comorbilidad baja 2 puntos y comorbilidad alta $>3$ puntos. Resultados: Evaluamos a 110 pacientes, con edad de $61+12$, predominó el género femenino $86 \%$. El antecedente de tabaquismo predominó en los pacientes con FPI 83\%, pacientes con IPAF con 
Neumol Cir Torax. 2019; 78 (4): 409-425

FVC más baja $(56 \% \pm 23 \%)$. El índice de Charlson resulto elevado con comorbilidad alta en todos los grupos, siendo mayor en los pacientes con NINE idiopática y secundaria. Conclusiones: En la cohorte estudiada se detectaron pacientes que sufren de dos o más comorbilidades deteriorando su calidad de vida, así como también aumentando su mortalidad. No fue mayor el índice de Charlson en pacientes con FPI como se esperaba, lo que indica que se tiene que atender las comorbilidades en todos los grupos de EPID y no sólo en la más agresiva de ellas.

\section{Hallazgos tomográficos más frecuentes de cáncer de pulmón (CP) en enfermedades pulmonares intersticiales difusas (EPID)}

\author{
María Fernanda Téllez-Quijada,* \\ Fortunato Juárez-Hernández, ${ }^{\ddagger}$ Miguel Octavio Gaxiola-Gaxiol, ${ }^{\ddagger}$ \\ Ana Karem Sauceda-Pruneda, ${ }^{\ddagger}$ Ivette Buendía-Roldán ${ }^{\ddagger}$ \\ *Universidad de Sonora; \#INER Ismael Cosío Villegas
}

Introducción: Las EPID son un grupo de entidades heterogéneas de comportamiento variable pero características clínicas, funcionales y radiológicas semejantes. Cifras de Globocan 2018, el cáncer con mayor incidencia y mortalidad mundial corresponde al $\mathrm{CP}$, con $11.6 \%$ y $18.4 \%$, respectivamente. En México, el CP ocupa el sexto lugar en incidencia y cuarto en mortalidad. La asociación entre $\mathrm{CP}$ y EPID es fundamentada por factores de riesgo comunes como hábito tabáquico, edad avanzada, medio ambiente o laboral, infecciones virales y lesiones crónicas del tejido. Hipótesis: La forma de presentación más frecuente de CP y EPID es masa única. Objetivo: Determinar características demográficas, histopatológicas y tomográficas en pacientes con CP y EPID. Material y métodos: Estudio retrospectivo realizado en el INER. Evaluamos características demográficas, histopatológicas y tomográficas. Resultados: Estudiamos 15 pacientes con EPID y CP. Género masculino 80\% $(n=12)$, edad 70+6 años; $100 \%$ con hallazgos de EPID en TACAR, $80 \%$ debutaron con masa. El patrón clínico más reportado fue síndrome combinado (SC) $40 \%(\mathrm{n}=6)$, seguido de NINE $27 \%$ $(\mathrm{n}=4)$, el patrón tomográfico más frecuente fue usual $73 \%(\mathrm{n}=$ 11), enfisema con $54 \%(n=8)$, al separarlo por tipos: $38 \%(n=3)$ centrolobulillar, $38 \%(\mathrm{n}=3)$ centrilobular y paraseptal. Catorce pacientes (93\%) presentaron hallazgos extrapulmonares, ocho $(53 \%)$ hallazgos extratorácicos y ocho (53\% metástasis). El diagnóstico histopatológico fue $60 \%$ adenocarcinoma. Conclusiones: Se ha descrito alta incidencia de CP y SC con masa única como forma de presentación. Por ello, deben desarrollarse métodos cuantitativos estándares para el diagnóstico de SC.

\section{Loperamida como adyuvante para tratar tuberculosis ocasionada por micobacterias tuberculosas y no tuberculosas}

Diego Alfonso Casto-Villeda,

Omar Morales-Barrientos, Esmeralda Juárez-Carvajal, Yolanda González-Hernández, Silvia Guzmán-Beltrán

INER ISMAEL Cosío VILLEGAS

La tuberculosis (TB) es causada por Mycobacterium tuberculosis. La TB se caracteriza por la aparición constante de casos resistentes a los medicamentos y se confunde por la incidencia de TB por micobacterias no tuberculosas (MNT). Las MNT son naturalmente resistentes a los medicamentos contra la TB. Si bien, los nuevos medicamentos en desarrollo pueden parecer prometedores, su eficacia y seguridad aún no se ha validado. Una alternativa para abordar estos desafíos terapéuticos es la reutilización de medicamentos aprobados por la FDA. Recientemente demostramos que la loperamida es un potente inmunomodulador. La loperamida es un derivado de la fenilpiperidina altamente lipófilo comúnmente utilizado para tratar la diarrea aguda y crónica infecciosa y no infecciosa. El objetivo fue evaluar su efecto bactericida contra $M$. tuberculosis, M. bovis $B C G, M$. terrae y $M$. smegmatis y determinar su efecto sinérgico con otros antibióticos. 1 x $10^{5}$ bacterias se les adicionó $100 \mu \mathrm{L}$ de loperamida (1000- $10 \mu \mathrm{g} / \mathrm{mL}$ ) y se incubaron de dos a cinco días. Luego se evaluó su efecto sobre el metabolismo bacteriano y sobre la supervivencia por UFC y se reportó la concentración mínima inhibitoria (CMI). La loperamida exhibió un efecto inhibitorio contra todas las especies de micobacterias, con CMI de 100 y 150 $\mu \mathrm{g} / \mathrm{mL}$ a concentraciones adecuadas para uso humano. Por ello, la loperamida podría usarse como terapia complementaria que puede sinergizar con los antibioticos comúnmente utilizados para tratar la tuberculosis y la MNT.

\section{Estimación de casos de influenza en unidades centinela en Aguascalientes durante las semanas epidemiológicas 40 del 2018 a la 20 del 2019}

Víctor Rafael Molina-Hernández,* Nidia Rodríguez-Plascencia ${ }^{\ddagger}$

*Instituto de Servicios de Salud del Estado de Aguascalientes; ‡INER ISMael Cosío Villegas

Introducción: En Aguascalientes, el registro más confiable para reporte de casos sospechosos de influenza de Enfermedad Tipo Influenza/Infección Respiratoria Aguda Grave (ETI/IRAG) es el reportado en la plataforma del SINAVE, donde se recaban datos de unidades centinelas de primer y segundo nivel de atención médica, y que son alimentadas con datos del IMSS, ISSSTE y SSA a través de Unidades de Salud Monitoras de Influenza (USMI). Objetivo: Analizar porcentaje de casos sospechosos de influenza en casos con infecciones respiratorias agudas de unidades de primer y segundo nivel de atención en la temporada de influenza 2018-2019 reportados por las USMI, y el porcentaje de casos positivos a influenza en pacientes con ETI/IRAG. Material y métodos: Estudio descriptivo, ecológico, observacional, retrospectivo. Análisis de casos de IRAS reportados por USMI en el estado de Aguascalientes, se estima proporción de casos que son sospechosos de influenza. Resultados: en USMI Hospitalarias, el porcentaje de sospecha de influenza con respecto a las IRAS fue de $6.7 \%$. De las muestras de laboratorio extraídas con buena calidad a pacientes con sospecha de influenza, en el $67.3 \%$ el resultado fue negativo, $29.8 \%$ tuvo resultado positivo para influenza y en el $2.9 \%$ dio resultado positivo para otros virus respiratorios. En las USMI de 1er. nivel de atención, el porcentaje de sospecha fue del $0.6 \%$. De las muestras de laboratorio extraídas con buena calidad a pacientes con sospecha de influenza, en el $60 \%$ el resultado fue negativo, $38.9 \%$ tuvo resultado positivo para influenza y en el $1.1 \%$ dio resultado positivo para otros virus respiratorios. Conclusiones: En hospitales de USMI 1.4 de cada 100 IRAS reportadas dieron positivo para influenza. En unidades de primer nivel de atención 0.5 de cada 1,000 IRAS dio positivo para influenza; sin embargo, su porcentaje de muestreo es solamente $24.3 \%$. 


\section{Plan de mejora a la sistematización del programa de materiales, sustancias y residuos peligrosos FMS4}

Martín Falcón-Concepción,* Jesús Hernández-Juárez, Mónica Azurim Valdez-Lino, ${ }^{\ddagger}$ María del Carmen Sarabia-León, Neddy Flores-Sánchez, ${ }^{\ddagger}$ María Angélica Velázquez-González ${ }^{\ddagger}$

\section{*UNAM; ‡INER ISMAEL COSÍO VILLEGAS}

Introducción: El propósito del estándar FMS4 es implementar el Programa de Materiales, Sustancias y Residuos Peligrosos (PMSyRP) de manera sistemática en todas las áreas que se almacenan, manipulan, utilizan y desechan materiales peligrosos, identificando y controlando de manera segura los MSyRP. Posteriormente se realiza un listado de MSyRP de acuerdo con su nivel de riesgo, colocando estratégicamente su ubicación de los materiales y su HDS en forma digital. Objetivo: Proponer un plan de mejora del PMSyRP, para poder identificar y controlar los MSyRP que se encuentran ubicados dentro de la Dirección de Investigación del INER derivado de las observaciones y sistematización del proceso de certificación. Métodos: De acuerdo con el Plan de Seguimiento del estándar FMS enfocado a procesos del PMSyRP, se hace una evaluación del proceso de identificación y del listado de los MSyRP de investigación: nombre químico, CAS, HDS, identificación de riesgo, entre otros. Resultados: Se tienen 35 áreas de investigación: 83\% cuentan con su listado actualizado. Del total de áreas que cuentan con su listado, $52 \%$ no comprueban tener sus HDS en forma digital, $17 \%$ no reportan el número de identificación CAS y $21 \%$ no específica la información de las categorías de peligro de algunas sustancias, lo cual impacta en el desarrollo del Plan de Mejora. Conclusiones: En la actualidad existe un cumplimiento parcial del estándar FMS4. Una de las estrategias para la mejora es la generación de un procedimiento que contiene las acciones concretas, los compromisos y el tiempo de cumplimiento para las diferentes áreas que servirán como barreras de seguridad. El plan de mejora tendrá efecto en la sistematización del PMSyRP.

\section{Repercusión de la dieta materna alta en sacarosa sobre el pulmón de rata neonatal}

Héctor Javier Nava-Reyes, Pedro Zamudio-Cortes, Luis Felipe Domínguez-Robert, Juan Francisco Nava-Aguirre, Guadalupe Hiriart-Valencia, Erika Liliana Monterrubio-Flores

\section{INER Ismael Cosío Villegas}

Antecedentes: Estudios epidemiológicos sugieren que el consumo materno de alimentos con alto contenido de azúcares no sólo causa problemas metabólicos o cardiovasculares en mujeres embarazadas, sino también provoca diversos efectos sobre el desarrollo fetal y salud postnatal. Objetivo: Observar la morfología y peso pulmonar del neonato de madres con dieta alta en sacarosa. Método: Ratas hembras wistar albino de 65-80 g de peso y cuatro semanas de edad fueron divididas al azar en dos grupos. Grupo control sin sacarosa (CSS) y experimental con sacarosa (ECS) antes y durante el embarazo. Las hembras se alojaron con los machos para la copula en la semana 15. Registramos el peso corporal y concentraciones de glucosa de la madre, así como peso corporal y pulmonar de los neonatos. Los pulmones fueron colectados para examinación histológica. Resultados: El peso corporal materno del grupo experimental (ECS) fue mayor comparado con el grupo control (CSS). Los niveles de glucosa sanguínea del grupo (ECS) aumentó previo al embarazo y disminuyó paulatinamente conforme evolucionó la gestación hasta aproximarse a los basales. Los neonatos del grupo (ECS) fueron significativamente de menor peso corporal y pulmonar $\left(6.980 \pm 0.493^{*} \mathrm{~g}, 0.164 \pm 0.022 * \mathrm{~g} ; * \mathrm{p}<0,05\right)$ que los del grupo (CSS) $(7.854 \pm 0.497 \mathrm{~g}, 0.189 \pm 0.005$ g). Histológicamente los pulmones del grupo (ECS) mostraron espacios aéreos colapsados, engrosamiento de pared alveolar y aumento en depósitos glucógeno comparado con el control (CSS). Conclusión: La dieta materna alta en sacarosa afecta el peso y maduración pulmonar del neonato, así como afecta el peso materno y concentraciones de glucosa. Los resultados de este estudio sugieren que el consumo de sacarosa debe limitarse antes y durante el embarazo para reducir cualquier efecto adverso sobre la madre y a largo plazo a su descendencia.

\section{Cambios en el inmunofenotipo de células NK en pacientes con diferentes formas clínicas de tuberculosis}

\section{José Alberto Choreño-Parra,}

Luis Armando Jiménez-Álvarez, ${ }^{\ddagger}$ Marcela Muñoz-Torrico, ${ }^{\ddagger}$ Citlaltepetl Salinas-Lara, ${ }^{\S}$ Joaquín Zúñiga-Ramos ${ }^{\ddagger}$

*Instituto Politécnico Nacional; ‡INER Ismael Cosío Villegas; §INNN «MANUEL VELASco SuÁreZ»

Introducción: Recientemente se ha propuesto la participación de las células NK en la inmunidad contra Mycobacterium tuberculosis (Mtb), incluyendo la descripción de subpoblaciones celulares con capacidad de montar respuestas de memoria. Sin embargo, su relevancia no ha sido bien caracterizada en humanos. Hipótesis: Las células NK participan en los mecanismos de inmunidad protectora subyacentes a la variabilidad clínica de la tuberculosis (TB), por lo que existen diferencias en el fenotipo de dichas células entre individuos con distintas formas clínicas de la enfermedad. Objetivo: Caracterizar el inmunofenotipo de células NK en individuos con distintas formas clínicas de TB. Material y métodos: Estudio observacional, transversal, descriptivo y comparativo en sujetos con TB latente (TBL), TB pulmonar (TBP) y TB meníngea (TBM). Se realizo una caracterización del inmunofenotipo de células NK obtenidas de sangre periférica mediante citometría de flujo. Se compararon las proporciones de células NK pertenecientes a los subtipos CD56bright y CD56dimCD16+, así como a las subpoblaciones de memoria CD45RO+ y CD56+CD27+. Resultados: Se incluyeron 11 pacientes con TBL, 27 con TBP y 10 con TBM. Los sujetos con TBM mostraron menor proporción de células NK CD56bright con relación a pacientes con TBL $(\mathrm{p}<0.0001)$ y TBP $(\mathrm{p}<0.01)$, así como mayor porcentaje de células NK CD56dimCD16+ respecto a los mismos grupos (TBL, $\mathrm{p}<0.05$; TBP, $\mathrm{p}<0.01$ ). No hubo diferencias en la proporción de células NK pertenecientes a las subpoblaciones de memoria CD45RO+ y CD56+CD27+. Conclusiones: las diferencias observadas en nuestro estudio apoyan la participación de las células NK en la inmunidad contra TB en humanos.

\section{Perfil proteómico del músculo liso: RG1- NHLRC1 como posibles reguladores de la hiperreactividad de las vías aéreas}

Marisol Álvarez-González, Mayra Dinorah Álvarez-Santos, Blanca Margarita Bazán-Perkins, Ivonne Pacheco-Alba, Yazmin Pérez-del Valle, Elizabeth Eslava-de Jesús

INER Ismael Cosío VILlegas 
Neumol Cir Torax. 2019; 78 (4): 409-425

El estudio proteómico de muchas enfermedades, incluida el asma, ha permitido dilucidar procesos de señalización y marcadores biológicos útiles para la medicina personalizada. En el asma el mecanismo principal que contribuye al estrechamiento excesivo (hiperreactividad) de las vías aéreas es la contracción anormal del músculo liso (MLVA). Nuestro objetivo fue analizar el perfil proteómico presente en el MLVA de cobayos de un modelo de asma alérgica con el fin de identificar proteínas asociadas con la hiperreactividad. En el MLVA de estos cobayos, mediante electroforesis de una y dos dimensiones se obtuvieron bandas y puntos con pesos moleculares entre 15 a $230 \mathrm{kDa}$. El análisis con MALDI/TOF-TOF-MS/MS identificó 76 proteínas; entre éstas, las que aumentaron su expresión fueron RG1, FLNA, ANXA5, COL1A1, SPG7, LIM2, TPM, FAM3A, DES, TEX15, PRKDC, SEMA3F, CNN1 y NET1. Se generó un perfil molecular y de interacción proteíca que mostró una asociación inversa entre RG1, una proteína asociada con el metabolismo de glucógeno, y NHLRC1, una proteína encargada de marcar a las subunidades reguladoras de glucógeno para su degradación. Por otro lado, una de las proteínas más importantes para la regulación de la relajación del músculo liso (MYPT1) no se expresó por espectrometría de masas en el asma. Lo anterior se corroboró por inmunohistoquímica, en donde un análisis digital en ImageJ-Fiji, no mostró diferencias de expresión para la proteína. En conclusión, no se observa un aumento de expresión de MYPT1 en el asma, lo que descartaría su papel como regulador principal de la hiperreactividad de las vías aéreas. Nuestros datos sugieren nuevas vías de señalización y proteínas; algunas de ellas no descritas en el asma, siendo la vía que involucra a RG1 y NHLRC1 como un posible mecanismo de regulación de la contracción del MLVA. Estudio parcialmente financiado por el fondo de Ciencia Básica SEP-CONACyT (\# 256197).

\section{Coccidioidomicosis y tuberculosis: similitudes y diferencias clínicas y epidemiológicas en pacientes hospitalizados en tercer nivel de atención en México}

\section{Anjarath Lorena Higuera-Iglesias, ${ }^{*}$ Toshie Manabe-Teikyo, ${ }^{\ddagger}$ Gabriel Palma-Cortez,* Blanca Ortiz-Quintero, ${ }^{*}$ María Eugenia Vázquez-Manríquez, ${ }^{*}$ Koichiro Kudo-Waseda ${ }^{\S}$ \\ *INER Ismael Cosío VIllegas; ‡University School of Medicine, Tokyo, Japan; §University Organization for Regional and Inter-Regional Studies, Tokyo, Japan}

Introducción: La coccidioidomicosis es una infección fúngica sistémica causada por Coccidioides-immitis o Coccidioides-posadasii. Se estima que aproximadamente el $5 \%$ de las personas infectadas desarrollan enfermedades crónicas y diseminadas. La tuberculosis activa y la coccidioidomicosis pulmonar crónica comparten algunos factores de riesgo y síntomas comunes. Objetivos: Describir las similitudes y diferencias cínicas y epidemiológicas entre la coccidioidomicosis y la tuberculosis para ayudar al diagnóstico temprano. Métodos: Se realizó un estudio retrospectivo en el INER. Se incluyeron pacientes con diagnóstico confirmatorio de coccidioidomicosis y tuberculosis entre 1992 y 2016, los grupos fueron pareados por edad y el sexo. Análisis estadístico: se compararon los datos de pacientes con coccidioidomicosis y TB, empleamos la prueba U de Mann-Whitney para variables continuas y la prueba chi cuadrada y la prueba exacta de Fisher para variables categóri- cas, se empleó SPSS ver. 22, se consideró niveles de significancia con un valor $\mathrm{p}<0.05$, dos colas. Resultados: Se compararon 110 pacientes por grupo. Las principales diferencias $(p<0.5)$ en pacientes con coccidioidomicosis se dividieron: 1) Características sociodemográficas: ingreso económico con una mediana $\$ 1,800$ m.n. versus \$ 2,550 m.n. por mes, mayor de analfabetismo, y viviendas con materiales poco perdurables en áreas suburbanas y rurales, antecedentes de residencia en zonas endémicas. 2) La condición de salud con exposición al tabaco y comorbilidades fueron similares. 3) Clínicamente se presenta menos diseminación, mayor exacerbación sintomatológica y complicaciones, con una puntuación mayor del CURBS y APACHE, estancia hospitalaria (mediana 26 versus 14 días) y mortalidad similar. Conclusiones: Las similitudes de estas patologías dificultan el diagnóstico, y pacientes hospitalizados inician tratamientos antituberculosos no justificados en un $67 \%$. Se sugiere hacer diagnóstico diferencial de coccidioidomicosis en pacientes con un patrón pulmonar de lesiones de tipo miliar, especialmente cuando el paciente tiene una deficiencia inmunológica con o sin antecedente de residencia en áreas endémicas para la coccidioidomicosis o cuando tienen una enfermedad respiratoria de mala evolución.

\section{Estudio de mecanismos bactericidas de polimorfonucleares (PMN) de pacientes con diabetes mellitus tipo 2}

\section{Alejandra González-Hernández,* \\ María Teresa Herrera-Barrios, ${ }^{\ddagger}$ Laura Carreto-Binaghi, \\ Esmeralda Juárez-Carvajal, ${ }^{\ddagger}$ Guadalupe Fabián-San Miguel $^{\ddagger}$

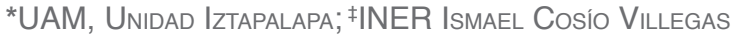

Introducción: La diabetes mellitus tipo 2 (DM2) representa un problema de salud a nivel mundial y los pacientes presentan mayor susceptibilidad a infecciones. Esto puede deberse a una respuesta inmune deficiente causada por la hiperglucemia. Los PMN participan en la eliminación de patógenos mediante la generación de especies reactivas de oxígeno (ERO's) (mieloperoxidasa (MPO), la NADHP oxidasa y producción de trampas extracelulares de ADN (NET's). Hipótesis: En la DM2 la hiperglicemia causa disminución en la producción de ERO's y las NET's contribuyendo a la susceptibilidad a las infecciones. Objetivo: Investigar el efecto de la hiperglicemia sobre la producción de ERO's y NET's en los PMN y MN infectados con M. tuberculosis y C. albicans. Material: Sangre de pacientes con DM2 y voluntarios sanos. Métodos: En PMN purificados no infectados e infectados con M. tuberculosis y C. albicans se analizó la actividad de MPO y se reportó en porcentaje de células positivas. La producción de ERO's se estudió durante la infección en sangre, en presencia de la sonda fluorescente CH2DCFDA, seguido de la tinción con CD66bPerCp-Cy5 (PMN), CD14PE (MN) y se hizo el análisis por citometría reportando porcentaje de células positivas. Adicionalmente, en PMN estudiamos la formación de NET's durante la infección haciendo la tinción para DNA y reportando en porcentaje. Resultados: No encontramos diferencias significativas de la actividad de MPO entre los grupos de estudio. Por otra parte, la producción de EROS (MN y PMN) aumentó con la infección; sin embargo, los resultados fueron comparables entre ambos grupos. Interesantemente en los PMN de pacientes se observó reducción en la producción de NETS. Conclusiones: En los pacientes con DM2 
Neumol Cir Torax. 2019; 78 (4): 409-425

la hiperglicemia no afecta el mecanismo bactericida asociado a MPO y producción de ERO's. Sin embargo, la reducción en NET's sugiere que la hiperglicemia afecta este mecanismo contribuyendo a la susceptibilidad a las infecciones.

\section{Sarcoma de Kaposi. Una variante inusual en ganglio linfático}

Natalia Aguirre-Vasquez, María Eugenia Vázquez-Manríquez, Laura Marcela Ospina-Restrepo, Ricardo Stanley Vega-Barrientos

INER ISMael Cosío VILLEGas

Introducción: El sarcoma de Kaposi es un trastorno angioproliferativo asociado a la infección por el herpes virus 8 en los paciente con VIH/SIDA. La introducción de la terapia antirretroviral generó una disminución de su incidencia, sin embargo, sigue siendo la principal neoplasia que se presenta en estos pacientes. Múltiples variantes morfológicas han sido descritas en las lesiones cutáneas, pero a nivel visceral y en ganglios linfáticos la presentación suele tener las características histológicas usuales. Materiales y métodos: Hombre de 26 años con dos meses de diagnóstico de VIH y sarcoma de Kaposi cutáneo en tratamiento con terapia antirretroviral y un ciclo de quimioterapia. Ingresa a urgencias por cuadro de fiebre, cefalea, tos emetizante, disnea y progresión de lesiones cutáneas. TAC de torax: parénquima pulmonar con nódulos centrilobulillares, engrosamiento del intersticio peribroncovascular, derrame pleural bilaterales y linfadenopatías cervicales, mediastinales, axilares, abdominales y retroperitoneales. A pesar de manejo presenta falla respiratoria, falla renal y choque, falleciendo dos días posteriores al ingreso. Resultados: En los ganglios linfáticos microscópicamente se observan extensas áreas fibrohialinizadas con luces vasculares con atipia citológica endotelial, inmunorreactivas para CD31, CD34 y HV8. Conclusiones: La variante esclerosante del sarcoma de Kaposi no ha sido descrita en el ganglios linfáticos, si bien cambios similares pueden presentarse en los casos de regresión, nuestro paciente no presentó datos clínicos ni imagenológicos de respuesta a tratamiento, por el contrario, las lesiones y el compromiso general progresó hacia un desenlace fatal.

\section{Hallazgos y patrones radiológicos identificados en tomografías de pacientes con linfoma nasal en México}

\section{Marian Elisa Radillo-Gil,* Arturo Iván González-González,* Ernesto Fernando Martín-Biasotti, Jorge Enrique Ortiz-Gallegos, ${ }^{\neq}$ Angélica Margarita Portillo-Vásquez, ${ }^{*}$ Armando Castorena-Maldonado* \\ *INER Ismael Cosío Villegas; 沼STItuto de Oftalmología FAP «Conde de Valenciana»}

Introducción: El linfoma nasal es de difícil diagnóstico clínico y alta mortalidad. No se cuenta con un patrón radiológico específico en tomografía para México, donde el linfoma de células T/NK representa el $40 \%$ de todos los linfomas no Hodgkin de células T. Se ha descrito en China y Corea la presencia de engrosamiento de la mucosa a nivel del septum y piso nasal mayores a 2.5 y $2 \mathrm{~mm}$, respectivamente, además de otros hallazgos que orientan a un patrón específico. Métodos: Se solicitaron datos de los pacientes diagnosticados con tumor nasal en los últimos cinco años, se revisaron para identificar a los diagnosticados con linfoma nasal y se solicitaron sus tomografías para evaluación por médicos radiólogos. Se seleccionaron 10 pacientes con diagnóstico de rinosinusitis crónica no polipoidea (RSC) y 10 con diagnóstico de granulomatosis con poliangitis (GPA). Se proporcionó una lista de cotejo con las características más probables de ser específicas de linfoma para su llenado por paciente. Se realizó análisis estadístico por medio de chi cuadrada, U de Mann Whitney, Wilcoxon o Kruskal Wallis según fuera necesario, además curva ROC y análisis de prueba diagnóstica. Resultados: 19 pacientes con diagnóstico de linfoma nasal, 11 RSC y 10 GPA, de los cuales se evaluaron 17 con linfoma, 10 RSC y 10 GPA. Diferencias en la ocupación del seno etmoidal anterior (derecho 0.077, izquierdo 0.255, contra RSC izquierdo 0.074 derecho 0.009 ), grosor de la mucosa septal (4.27 versus 2.21 versus 2.23 , p 0.003 con Kruskal Wallis) y la neosoteogénesis del maxilar, con una p contra GPA de 0.024 en izquierdo y 0.07 en derecho. Compilando las características significativas mucosa se encontró un AUC de 0.25 , con sensibilidad de $88 \%$ y especificidad de 45\%. Conclusión: Se encontraron hallazgos que pueden llevarnos a contar con una escala para el diagnóstico radiológico específico de linfoma nasal.

\section{Control de infección por patógenos intracelulares mediada por leucocitos en pacientes con diabetes mellitus tipo 2}

Ana Karen Ramírez-Moreno, * Silvia Guzmán-Beltrán, Yolanda González-Hernández, ${ }^{\ddagger}$ Gabriela Rosas, María Teresa Herrera-Barrios ${ }^{\ddagger}$

*UNAM; ‡INER ISMAeL Cosío VILLEGAS

Introducción: La diabetes mellitus tipo 2 (DM2) es un problema de salud pública. Los pacientes con DM2 presentan alteraciones en su respuesta inmunológica debido a los macrófagos y neutrofilos (Neut) involucrados en la fagocitosis y mecanismos intracelulares que participan en la eliminación de patógenos intracelulares como M. tuberculosis $(M t b)$ y C. albicans. Actualmente hay modelos de infección in vitro en células aisladas simulando las condiciones fisiológicas en pacientes con DM2. Sin embargo, no se ha reportado algún modelo de infección en sangre total de pacientes con DM2. Hipótesis: En la DM2 la hiperglucemia causa disminución en la fagocitosis y el control del crecimiento intracelular de patógenos. Objetivo: Estudiar la fagocitosis y capacidad de control del crecimiento de $M t b$ y $C$. albicans por los leucocitos de sangre periférica (PMN y monocitos) en pacientes con DM2. Material: Sangre de pacientes con DM2 y voluntarios sanos. Método: Se hizo la infección en sangre con $M t b$ y $C$. albicans y se analizó la fagocitosis después de $1 \mathrm{~h}$ seguida de la lisis de eritrocitos y preparación del frotis para tinción (Wright y Kinyou) y análisis en microscopio reportando en porcentaje de células postivas. El control de crecimiento intracelular se hizo a 1, 4 o 24 h postinfección mediante el cultivo del lisado celular reportándose como unidades formadoras de colonia (UFC). Resultados: La fagocitosis de $M t b$ y $C$. albicans mostró un aumento discreto en los pacientes llevada a cabo principalmente por los Neut, aunado al incremeto de las UFC de Mtb y C. albicans. Conclusión: La fagocitosis y el control del crecimiento intracelular son modificados por la hiperglucemia de los pacientes con DM2 y esto puede contribuir a la susceptibilidad a infecciones. 


\section{Análisis de variantes genéticas en TLR2 y TLR4 asociadas a EPOC}

\author{
Mario Alberto Islas-López,* Gloria Pérez-Rubio, ${ }^{\ddagger}$ \\ Ramcés Falfán-Valencia, ${ }^{\ddagger}$ Alejandra Ramírez-Venegas ${ }^{\ddagger}$ \\ *UAM Unidad Xochimilco; ‡INER Ismael Cosío Villegas
}

Introducción: La enfermedad pulmonar obstructiva crónica (EPOC) es ocasionada por exposición significativa a partículas o gases nocivos. La exposición al humo proveniente de la quema de biomasa es un factor de riesgo considerable en países emergentes. Se ha propuesto que el humo de biomasa podría provocar una respuesta inflamatoria que depende de la activación de receptores tipo Toll en macrófagos y células epiteliales de vías aéreas, lo cual contribuye al desarrollo de dicha patología. Hipótesis: Existen polimorfismos en TLR2 y TLR4, asociados a EPOC secundaria a humo de la quema de biomasa. Objetivo: Asociar polimorfismos en TLR4 (rs4986791) y TLR2 (rs5743708, rs5743704, rs3804099, rs3804100) en pacientes con EPOC secundaria a quema de biomasa. Material y métodos: Se incluyeron 244 participantes clasificados en dos grupos: aquel compuesto de pacientes con EPOC secundaria a quema de biomasa $(E P, n=77)$ y el segundo de mujeres expuestas a humo de biomasa sin EPOC (EHB, $n=167)$. Se evaluaron cinco polimorfismos descritos anteriormente por PCR en tiempo real en su modalidad de discriminación alélica. El análisis de resultados se llevó a cabo mediante SPSS v 15 y Epidat versión 3.1. Resultados: De los cinco SNPs evaluados, no se obtuvieron datos significativos. Conclusiones: Los polimorfismos evaluados en el estudio no se encuentran asociados con la EPOC en pacientes expuestas a humo proveniente de la quema de biomasa.

\section{Potencial toxigénico de aislados clínicos y ambientales de Aspergillus flavus}

\section{Jaqueline A. Cortés-Dávila, ${ }^{*}$ Rodrigo Cardoso-de Oliveira, Gabriel Palma-Cortés, ${ }^{\S}$ I. Jesús Resendiz-Sánchez," Magda Carvajal-Moreno, "l Carlos Cabello-Gutiérrez ${ }^{\S}$ \\ *Universidad Autónoma de Tlaxcala; łUniversidad de SaO

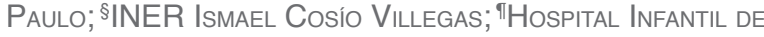 México Federico Gómez; "InStituto de Biología}

Introducción: Las aflatoxinas son metabolitos secundarios tóxicos producidos por Aspergillus flavus. La necesidad de investigar estas toxinas ha crecido en los últimos años debido a su alta incidencia en alimentos de consumo masivo y a su toxicidad. La aflatoxina B1 (AFB1) es como evidente cancerígeno en animales de experimentación, convirtiéndose en la aflatoxina de mayor importancia en salud pública. Objetivo: Caracterizar el potencial toxicogénico de cepas clínicas y ambientales de Aspergillus flavus para producir aflatoxina B1 (AFB1) a través de HPLC. Material y método: Los aislamientos fueron inoculados en placas PDA, las esporas se recuperaron lavando la superficie con solución salina fisiológica y Tween-80. Las esporas recolectadas se enumeraron en cámara de Neubauer; esta suspensión ajustada se utilizó como inóculo para la determinación de la producción de aflatoxinas en dos medios de cultivo diferenciales (CAM y YES). Para la extracción de aflatoxinas se licuó el contenido de cada placa con metanol grado HPLC, utilizando columnas de inmunoafinidad para aflatoxinas totales, realizando así la elución de las muestras; por último, se procedió a una derivatización para la cuantificación por HPLC. Resultados: La producción de aflatoxinas fue mayor en medio diferencial de coco en todos los aislados, visualizado en luz UV de larga onda (360-365 $n m)$. La cuantificación de HPLC arrojó una mayor producción de aflatoxina B1 (AFB1) de los aislados clínicos con un promedio de $2227.65 \mathrm{ng} \mathrm{mL}^{-1}$ en comparación con los aislados ambientales de tan solo $396.18 \mathrm{ng} \mathrm{mL}^{-1}$. Conclusiones: Los aislados clínicos produjeron una mayor cantidad de aflatoxina B1 (AFB1) en comparación que los aislamientos ambientales.

\section{Papel de las proteínas ROCK1/2 y SERCA2b como} mediadores de la hiperreactividad de las vías aéreas

\author{
Elizabeth Eslava-de Jesús, Marisol Álvarez-González, \\ Mayra Dinorah Álvarez-Santos, \\ Blanca Margarita Bazán-Perkins, \\ Ángel Arturo González-López, Ivonne Pacheco-Alba \\ INER ISMAEL Cosío VILlegas
}

La hiperreactividad es una de las principales características del asma y se caracteriza por una contracción excesiva del músculo liso de las vías aéreas (MLVA). Algunas de las proteínas involucradas en la señalización de la contracción son la proteína cinasa asociada a Rho isoformas 1 y 2 (ROCK1, ROCK2), encargada de regular a la fosfatasa de la cadena ligera de la miosina, y la ATPasa de calcio del retículo sarcoplásmico (SERCA2b) del MLVA, proteína transmembranal que regula las concentraciones intracelulares de calcio durante la contracción y la relajación muscular. El objetivo de este trabajo fue determinar la relación entre la hiperreactividad y la expresión de ROCK1/2 y SERCA2b en cobayos hiperreactores mediante inmunohistoquímica. Cobayos machos fueron sensibilizados con ovoalbúmina y sometidos a pruebas de hiperreactividad. Un análisis de expresión digital mediante el programa ImageJ-Fiji evaluó la expresión relativa de las proteínas presentes en el tejido pulmonar. Se observó un aumento de la expresión en epitelio de las vías aéreas para las tres proteínas en los cobayos sensibilizados, pero en el MLVA sólo la isoforma ROCK2 y SERCA2b presentaron un aumento significativo en estos cobayos. Se identificó una correlación negativa entre el aumento de la hiperreactividad y la expresión de la isoforma ROCK2 y SERCA2b. En conclusión, el aumento de expresión de las proteínas ROCK1, ROCK2 y SERCA2b en el epitelio de las vías aéreas de cobayos hiperreactores podría estar indicando no sólo un papel relacionado con la contracción excesiva del MLVA, sino también con otras vías de señalización en el epitelio. Es posible que ROCK2 y SERCA2b estén involucrados en la regulación de la hiperreactividad de las vías aéreas. Estudio parcialmente financiado por el fondo de Ciencia Básica SEP-CONACyT (\# 256197).

\section{Enfermedad respiratoria exacerbada por AINE, desenlace clínico tras desensibilización con aspirina y tratamiento concomitante con omalizumab}

Carlos José de León-Ralon, Fernando Ramírez-Jiménez, Luis Manuel Terán-Juárez, Gandhi Fernando Pavón-Romero

\section{INER Ismael Cosío VILlegas}

Introducción: El tratamiento de la EREA es multidisciplinario, incluye el manejo médico del asma y el tratamiento quirúrgico de 
la poliposis nasosinusal; a pesar de éste, los pacientes muestran recurrencia de los pólipos de manera frecuente. La desensibilización con aspirina es el único tratamiento capaz de modificar el curso de la enfermedad, y el tratamiento con anticuerpos monoclonales anti Ig-E (omalizumab) se ha demostrado efectivo en estudios clínicos y su mecanismo de acción subyace en la supresión de la producción de PGD2 y sobreproducción de cisteinil-leucotrienos más que la atenuación de la inflamación eosinofílica. Descripción del caso: Femenino de 55 años de edad diagnosticada con EREA a los 47 años, ésta cursa de manera progresiva, requiriendo dosis máxima de corticosteroide inhalado en combinación con LABA, además de múltiples intervenciones quirúrgicas para el tratamiento de la poliposis nasosinusal recidivante. En junio 2017 se realiza desensibilización con lisin aspirina en INER y de forma concomitante tratada con omalizumab, previamente indicado por asma grave. A partir de entonces existe mejoría clínica y de su calidad de vida medido por medio de los cuestionarios RQLQ y AQLQ; luego de 18 meses se observó, por medio de nasoendoscopia rígida, reducción de poliposis nasal grado III a ausencia de los mismos. Discusión: La desensibilización con aspirina es el único tratamiento modificador de la enfermedad y aunque el uso de omalizumab también se ha reportado efectivo, el tratamiento con la combinación de ambos no se ha explorado aún. Este caso demuestra la combinación de uso de omalizumab en una paciente posteriormente desensibilizada en nuestro Instituto, con evidencia objetiva en la reducción de la poliposis nasosinusal inicial en grado III hasta su ausencia 18 meses después, así como mejoría clínica y en su calidad de vida. Esto podría ser el parte aguas para el desarrollo de ensayos clínicos futuros en el cual se incluyan ambas modalidades de tratamiento en pacientes con EREA.

\section{Calidad de sueño en niños hospitalizados que cursan con enfermedades respiratorias en el Instituto Nacional de Enfermedades Respiratorias (INER)}

Sonia Verónica Gordillo-Nieto, Angélica Margarita Portillo-Vásquez, Emma García-Colin, Yadira Guadalupe Rodríguez-Reyes, Alejandro Alejandre-García

\section{INER ISMAeL Cosío VILlegas}

Introducción: El sueño es fundamental en el proceso de curación de las enfermedades, está involucrado en un adecuado funcionamiento del sistema inmune y la recuperación de las heridas. Durante las hospitalizaciones hay una disminución en la calidad del sueño, lo cual tiene importantes consecuencias en la evolución del paciente. Respecto a los pacientes pediátricos, hay pocos estudios que evalúan la calidad de sueño durante la hospitalización, y ninguno de ellos se enfoca en las enfermedades respiratorias ni estudia a los pacientes por más de una noche. Una de las formas objetivas para evaluar el sueño en niños es la actigrafía, la cual ha sido la forma más común para evaluar la calidad de sueño durante la hospitalización hasta ahora. Por lo tanto, nosotros pretendemos evaluar la calidad de sueño en los niños hospitalizados que cursan con enfermedades respiratorias (neumonía y crisis asmática), usando la actigrafía durante todo el tiempo de la hospitalización. Materiales y métodos: Todos los niños de 2.5 a 14 años hospitalizados en el Servicio de Neumología Pediátrica que cursen con neumonía o crisis asmática recibirán un actígrafo que usarán durante su internamiento. Además, se solicitará a los padres llenar un cues- tionario sobre los síntomas de sueño y hábitos en la casa; recibirán un diario de sueño y también se les solicitará llenar un registro horario de actividades. Algunos datos relevantes serán tomados del expediente hospitalario, incluyendo los momentos de las revisiones médicas o de enfermería. Al momento del egreso, el actígrafo será devuelto a los investigadores y la información será descargada para su análisis. El análisis estadístico analizará las diferencias en tiempo y calidad de sueño (reportadas como eficiencia) entre los grupos de enfermedades, las diferentes edades y con el tiempo recomendados por la AASM. Además, las causas más frecuentes de interrupciones del sueño serán reportadas y el cambio en el tiempo y calidad durante el tiempo de hospitalización serán analizados con ANOVA y una regresión mixta. Resultados: Una muestra de 48 niños fue calculada considerando que el tiempo de sueño total de 540 minutos ha sido reportado mientras que la recomendación es de 600 minutos. cuatro niños fueron reclutados desde el primero de julio de 2019. Todos estos niños habían sido hospitalizados con el diagnóstico de neumonía, dos niños y dos niñas con edades de $2.67,2.12,5.5$ y 3.57 años. De acuerdo a la actigrafía, los tiempos de sueño total y la eficiencia de sueño fue menor en los primeros días de internamiento, con un tiempo total de sueño (incluyendo siestas) en el rango de 557 a 707, y una eficiencia de sueño de 74.9 a 80.51 , ambas durante el internamiento y se encuentran cerca de las recomendadas para su edad al momento del egreso, con un rango de eficiencia de sueño de 85 a $90 \%$ y un tiempo se sueño 620 a 766. Luces y sonidos han sido reportados como los causantes más comunes de interrupción del sueño en niños. Conclusiones: Todos los niños incluyendo a aquellos que han mostrado baja eficiencia de sueño y un tiempo total de sueño durante la hospitalización. Esto podría relacionar sus síntomas al internamiento o tal vez, al fenómeno de primera noche. Mientras más pacientes sean incluidos en el protocolo, esperamos probar esta tendencia y encontrar datos que expliquen esto de forma satisfactoria.

\section{Calidad de sueño y trastornos respiratorios del dormir en pacientes con discinesia ciliar primaria}

\section{Lissette Carolina Rivas-Hernández,} Angélica Margarita Portillo-Vásquez,

Fidel Arturo Partida-Cervantes, Selene Guerrero-Zúñiga, Alejandro Alejandre-García, Martha Guadalupe Torres-Fraga

\section{INER Ismael Cosío Villegas}

Introducción: La discinesia ciliar primaria (DCP) es una enfermedad genética autosómica recesiva heterogénea, caracterizada por disfunción de la motilidad ciliar. Debido a su desconocimiento, no se diagnostica adecuadamente. El estándar de oro para el diagnóstico es mediante la identificación de la alteración en el axonema ciliar por microscopia electrónica. El tratamiento está orientado a evitar infecciones sinopulmonares y daño pulmonar crónico. El sueño en todos los niños es un proceso vital para el crecimiento y el desarrollo, y en esta población se ha observado alterado, con una calidad de sueño baja, presencia de apnea obstructiva del sueño y alteraciones en el intercambio gaseoso, principalmente hipoxemia. Sin embargo, los datos presentados en varios estudios son divergentes, con informes de prevalencia de apnea obstructiva del sueño en esta población entre 18 a $50 \%$. El objetivo del presente estudio es describir las características del sueño en niños con este diagnóstico de 3 a 18 años de edad, incluida la prevalencia de la apnea obstructiva del sueño. 
Materiales y métodos: Todos los padres de niños de nuestro centro con diagnóstico de DCP confirmado mediante microscopia electrónica fueron invitados a participar en el estudio. Los participantes que estuvieron de acuerdo tuvieron una cita en la Unidad de Medicina del Sueño donde se les pidió que contestaran cuestionarios acerca de síntomas durante el sueño (Cuestionario desarrollado en nuestro centro, así como el Cuestionario Pediátrico del Sueño ((PSQ)). Posteriormente se les asigno una fecha para realizar una polisomnografía. El estudio de polisomnografía está siendo realizado por técnicos de nuestro laboratorio de sueño y calificada de acuerdo al manual AAMS versión 2.5. Todas las polisomnografías incluyen medición dióxido de carbono transcutáneo o exhalado. Posteriormente el paciente se reunirá con los investigadores en una tercera visita para informar los resultados del estudio y recibir tratamiento en caso de requerirlo. Resultados: De los 32 pacientes con diagnóstico de DCP en nuestro centro, 23 han sido contactados con éxito y 20 han completado todos los cuestionarios mencionados previamente. Se reporta en estos niños una edad promedio de 9.85 años, siendo el de predominio de sexo masculino en $55 \%$, la mayoría (60\%) reside en el área metropolitana de la Ciudad de México. En promedio se acuestan alrededor de las 10 p.m. y se despiertan alrededor de las 7 durante la semana y a las 9 a.m. los fines de semana. Están expuestos de 2 a 3 horas por día a pantallas. El 55\% de estos pacientes toma siestas (más de una hora) a pesar de que todas tienen más de cinco años. El 35\% refiere insomnio de inicial y de mantenimiento, el $35 \%$ refiere miedo a la oscuridad y el $25 \%$ presenta resistencia a acostarse. $75 \%$ refieren ronquidos, $45 \%$ apneas observadas y $55 \%$ diaforesis. En el PSQ, el $80 \%$ presenta riesgo de apnea obstructiva del sueño. El $90 \%$ refiere movimientos mientras duermen, $65 \%$ somniloquios y $35 \%$ bruxismo, $35 \%$ refieren síntomas de la enfermedad de Willis-Ekbom. Contamos con los resultados de polisomnografía de 5 sujetos, 4 niños y 1 niña, con edades de 5 a 16 años con mediana de 9 años. La eficiencia de sueño varió de 82.6 a $96.6 \%$, con mediana de 89.5 , la latencia a sueño fue en mediana de 8 minutos y la latencia a MOR de 96.5 minutos, ambos dentro del rango normal. La saturación promedio varió de 86.9 a 95\%, con mediana de 95 , mientras que el tiempo con saturación por debajo del $90 \%$ de 0.1 a 90.2 , con mediana de 15.4. No se contó con pacientes que presentaran hipoventilación. 4 de los 5 pacientes cumplen con IAH mayor a 1 (o a 5 en los mayores de 12 años) por lo que tiene diagnóstico de SAOS por PSG. Conclusiones: Los niños de nuestro centro con diagnóstico de DCP presentan una prevalencia relativamente alta de trastornos del sueño, como insomnio y parasomnias de etapa No-MOR, y tienen una alta prevalencia de riesgo de apnea obstructiva del sueño y síntomas relacionados. Estos síntomas se correlacionarán con su evaluación objetiva en el PSG y nos permitirán una mejor evaluación y educación para estos pacientes.

\section{Calidad de sueño posterior a cirugía endonasal en pacientes con enfermedad respiratoria exacerbada por aspirina}

Mario Alonso Toledo-Varela, Angélica Margarita Portillo-Vásquez, Marcos Alejandro Jiménez-Chobillón, Armando Castorena-Maldonado

INER ISMAel Cosío VILlegas

Antecedentes: La enfermedad respiratoria exacerbada por aspirina (EREA) se compone de rinosinusitis crónica eosinofílica, asma bronquial, poliposis nasal e intolerancia a los antiinflamatorios no esteroideos. Se ha encontrado en estudios (y revisión sistemática de los mismos) mejoría en síntomas posterior a cirugía en estos pacientes; sin embargo, no se ha estudiado los cambios que pueden estar presentes en la calidad de sueño, habiéndose demostrado ya mejoría en la calidad de sueño en rinosinusitis crónica posterior a cirugía. Pregunta de investigación: ¿Existen cambios significativos en la calidad de sueño en los sujetos con enfermedad respiratoria exacerbada por aspirina posterior a la cirugía endoscópica nasal? Justificación: Una buena calidad de sueño es fundamental para la calidad de vida y prevención de enfermedades crónicas. Se ha encontrado alteración en la calidad de sueño en rinosinusitis crónica y asma, siendo ambos componentes de EREA. No se conoce actualmente si existe una mejoría posterior a la cirugía endoscópica endonasal. Metodología: Se está invitando a participar a los pacientes con diagnóstico de EREA y plan quirúrgico atendidos en la Clinica de IAPA del Departamento de Otorrinolaringología del INER. Se les aplica cuestionarios para evaluar síntomas nasales (SNOT-22) relacionados con asma (ACT), calidad de vida y calidad de sueño (Índice de Calidad de Sueño de Pittsburgh). Se les entrega, además, un actígrafo para la medición de actividad y movimientos en sueño, siendo devuelto el día de la cirugía. Se realiza la evaluación con cuestionarios nuevamente 1, 3 y 6 meses después de la cirugía y con actigrafía 3 y 6 meses posterior. Se analizarán los cambios en el ICSP entre el prequirúrgico y el sexto mes con t de Student, y los cambios a través del tiempo en la actigrafía con regresión de modelo mixto. Registro en clinical trials NCT03627481. Resultados: Al momento se han reclutado seis pacientes en el estudio, todas ellas de género femenino, con edades de 30 a 48 años, mediana de 43, todas ellas con diagnóstico de enfermedad respiratoria exacerbada por aspirina y hallazgo de poliposis nasal grado IV previo a manejo quirúrgico. En sus cuestionarios y actigrafía basal se encuentra que las pacientes presentan en SNOT-22 puntajes de 43 a 85 con mediana de 56, evidenciando sus síntomas nasales graves; en el ACT puntaje de 15 a 25, con mediana de 22.5, por lo tanto con presencia de asma bien controlada (necesaria para poder realizar intervención quirúrgica). En el ICSP se encuentra que presentan puntaje de 8 a 18, con media de 14, estando todas en el rango de necesitar atención médica y tratamiento o de tener trastorno del sueño grave. Todas refieren problemas para conciliar el sueño y tiempo de sueño menor a lo recomendado. En la actigrafía se tiene un tiempo total de sueño (en promedio de los siete días de medición) de 263 a 515 minutos, con una media de 349.55 , por lo que las pacientes presentan un tiempo de sueño mucho menor al recomendado. La eficiencia varió de 81.17 a 94.67, con una mediana de 90.06, alrededor de lo esperado para un adulto de estas edades. Conclusión: los pacientes evaluados presentan una afectación importante en el sueño, tanto subjetiva como objetiva en cuanto a sueño total. Esperamos que se observe una mejoría importante al reevaluar posterior al manejo quirúrgico.

\section{Incidencia de micosis pulmonares durante 27 años en} el Instituto Nacional de Enfermedades Respiratorias

Gabriel Palma-Cortés, Elba Lucía Valencia-Maqueda, Víctor Hernández-Hernández, Carlos Cabello-Gutiérrez, Víctor Sánchez-Nájera, Lorena Anjarath Higuera-Iglesias

\section{INER ISMAEL COSío VILLEGAS}

Introducción: Las micosis son enfermedades graves y potencial- 
Neumol Cir Torax. 2019; 78 (4): 409-425

mente letales, especialmente aquellas que presentan síntomas no específicos que dificultan el diagnóstico oportuno. En México, la ruta más común de las infecciones pulmonares por hongos es a través de la exposición a estructuras infectantes relacionadas con la actividad laboral y la estancia o visita a áreas endémicas. Objetivos: Conocer la casuística de las principales micosis pulmonares diagnosticadas en el INER. Material y métodos: Es un estudio retrospectivo, durante los años 1992 a 2018, datos tomados del Departamento de Bioestadística y Admisión Hospitalaria y Registros Médicos del INER. Se obtuvo un registro de 879 pacientes diagnosticados con micosis pulmonares. Resultados: Los datos analizados mostraron que las principales micosis pulmonares registradas son: neumocistosis (37.54\%), aspergilosis (20.47\%), histoplasmosis $(18.54 \%)$, coccidioidomicosis $(12.62 \%)$, micosis inespecíficas $(5.23 \%)$ entre otras de menor porcentaje. Para este estudio, candidiasis no se tomó en cuenta debido a que fue una afección oral y no pulmonar. Discusión: Las infecciones micóticas no son la primera opción diagnóstica en pacientes con enfermedad pulmonar, debido a la similitud con otras patologías como bacterianas y virales. No hay reportes confiables que nos brinden un panorama de estas micosis por lo que se necesitan estadísticas confiables en México. En este trabajo damos un panorama de las micosis pulmonares diagnosticadas en un hospital de tercer nivel. Conclusiones: Debemos de considerar a las micosis como parte fundamental del diagnóstico de enfermedades pulmonares y que sean consideradas como reporte obligatorio ante en Sistema Nacional de Vigilancia Epidemiológica.

\section{Alergia alimentaria en pacientes con asma y rinitis alérgica}

Olga Karen Bárcenas-Hernández

INER Ismael Cosío Villegas

Introducción: La alergia alimentaria (AA) es un efecto adverso para la salud que surge de una respuesta inmune específica, la cual es reproducible al exponerse a un alimento dado. Se ha demostrado que el asma y la alergia alimentaria suelen coexistir entre sí, especialmente porque a menudo comparten factores de riesgo. Objetivo: Evaluar el patrón de sensibilización a alimentos en pacientes con asma. Material y métodos: Se aplicó un cuestionario a los pacientes de la consulta externa del Departamento de Inmunogenética y Alergia con diagnóstico de RA y/o asma, aquellos con probables síntomas de AA se les realizó prueba confirmatoria por técnica de prick to prick. Resultados: Se identificaron 75 pacientes que referían algún síntoma de AA, de los cuales sólo a 31 se les realizo prick to prick; 55 alimentos fueron referidos como responsables de algún síntoma asociado a $\mathrm{AA}$, en cuyo caso fue el síndrome de alergia oral (SAO); siendo los más frecuentes durazno, manzana, aguacate y nuez, mediante prick to prick: todos los pacientes demostraron sensibilidad al menos a dos alimentos, siendo los de mayor frecuencia: manzana, durazno, fresa y aguacate y pera; las combinaciones con mayor frecuencia fueron durazno-fresa en $12.9 \%$, y aguacate-manzana $6.4 \%$. En relación a la concordancia entre el antecedente de síntomas y el pick to prick demostró una valor de kappa de 0.8 p $<0.001$ sólo para el durazno y manzana Estos alimentos fueron los asociados a SAO más que otro síntomas $\mathrm{p}<0.05$. Y el poseer la sensibilidad algún alimento no demostró implicaciones en la gravedad del asma. Conclusión: La alergia alimentaria es una enfermedad poco prevalente respecto a otras enfermedades alérgicas. De acuerdo con nuestros resultados no se encontró que la alergia alimentaria a frutas y verduras tenga un impacto negativo en el control del asma. De acuerdo a los estudios de concordancia el cuestionario es una herramienta útil para el diagnóstico de alergia al durazno, manzana y aguacate.

\section{Reinfección con coinfección de influenza en paciente pediátrico en la CDMX}

Víctor Alberto Hernández-Hernández, Anjarath Lorena Higuera-Iglesias, Dora Patricia Rosete-Olvera, Claudia Garrido-Galindo, Carlos Cabello-Gutiérrez

\section{INER ISMAEL Cosío VILLEGAS}

Introducción: Durante las temporadas de influenza ocurren reinfecciones y coinfecciones con los virus que causan la enfermedad; sin embargo, ambos eventos en un mismo paciente no se han reportado. Las guías de tratamiento a pacientes con influenza no tienen recomendaciones sobre este tipo de infecciones, y podría ocasionar un diagnóstico impreciso que puede llevar al paciente a desarrollar la forma grave de la enfermedad y comprometer su vida. Objetivo: Describir un caso de reinfección con coinfección de influenza en un paciente pediátrico, emitiendo recomendaciones para el uso de pruebas que ayuden a realizar un diagnóstico correcto y el adecuado tratamiento para estas infecciones. Método: En las tres consultas que asistió el paciente durante la temporada de influenza de 2017 se le realizó interrogatorio, exploración física, una prueba rápida de influenza (RIDT) y qRT-PCR para confirmar el diagnóstico. Además, durante el evento de reinfección con coinfección se realizó una placa de tórax, uroanálisis y biometría hemática. Resultados: El paciente previamente vacunado presentó un cuadro de enfermedad tipo influenza (ILI) en febrero de 2017, se diagnosticó con influenza B y se dio tratamiento con oseltamivir que resolvió la enfermedad. En marzo de 2017 llega con otro cuadro de ILI más severo que el anterior, esta ocasión se establece una reinfección con virus de influenza $\mathrm{B}$ que además se presentó en coinfección con el virus de influenza A H3N2, se administró oseltamivir que resolvió el cuadro clínico. En mayo del mismo año vuelve a la consulta con un cuadro febril que resolvió sin tratamiento y no relacionado con influenza. Conclusiones: Este es el primer caso de reinfección con coinfección, donde el uso de RIDT de alta sensibilidad fue crucial para realizar un diagnóstico correcto y permitió brindar un tratamiento oportuno con oseltamivir que resolvió la enfermedad y evitó la forma grave.

\section{Mycobacterium tuberculosis incrementa la frecuencia de macrófagos CD3+ TCR+}

\author{
Lucero de los Ángeles Ramón-Luing, \\ Claudia Carranza-Salazar, Yolanda González, \\ Leslie Chávez-Galán \\ INER ISMael Cosío Villegas
}

Introducción: Existe células mieloides que expresan la molécula CD3 y pueden o no coexpresar el TCR (CD3+TCR+, CD3+TCR-, respectivamente). En un modelo murino de infección con BCG se incrementa la frecuencia de estas subpoblaciones, aparentemente la 
vía del TNF es fundamental para regular el reclutamiento de estas células, y pacientes con tuberculosis también presentan acumulación de estas subpoblaciones, pero se desconoce si el grado de virulencia es determinante para generar estas subpoblaciones. Hipótesis: La frecuencia de células M-CD3+TCR+ es dependiente de la virulencia de Mycobacterium tuberculosis (Mtb). Objetivo: Evaluar la frecuencia de macrófagos humanos (MDM) CD3+ TCRab+ y TCRab- (M-CD3+TCR+/TCR-) en respuesta a la infección con Mtb H37Ra y H37Rv. Material y métodos: MDM se infectaron con H37Rv (MOI 1 y 5) y H37Ra (MOI 1 y 10) durante 24 h. Los MDM infectados se caracterizaron fenotípicamente (CD3, TCRab, TNF, MHC-II, Cd1b y Cd1c), y se evaluó el perfil de secreción de TNF, IFN- $\gamma$, IP-10 e IL-10. Resultados: Ambas cepas indujeron una frecuencia de 10-15\% de MDM-CD3+; H37Rv incrementó la frecuencia de M-CD3+TCR+ desde una MOI baja, mientras H37Ra requiere una MOI alta, consecuentemente, los M-CD3+TCR- disminuyeron. La virulencia fue determinante para la expresión de moléculas presentadoras de antígeno (MPA), H37Rv disminuyó la frecuencia de M-CD3+TCRab-HLA-II+, CD3+TCRab+CD1b+y CD3+TCRab-tmTNF+, en contraste, H37Ra incrementó la frecuencia de M-CD3+TCRab+CD1b, CD3+TCRab+CD1c y CD3+TCRabtmTNF+. La secreción de las citocinas también fue dependiente de la virulencia, MDM infectados con $\mathrm{H} 37 \mathrm{Rv}$ secretan altas cantidades de IFN- $\gamma$, IP-10, TNF e IL-10 desde una MOI baja, mientras que con H37Ra solo secretan TNF e IL-10 a una MOI alta. Conclusiones: A tiempos cortos de infección, la virulencia de $M t b$ incrementa la presencia de M-CD3+TCR+, además afecta la expresión de MPA necesarias para el control de la infección por $M t b$, así como el perfil de secreción de las citocinas.

\section{Identificación de reclutamiento de macrófagos CD3+ durante la tuberculosis pulmonar progresiva murina}

Marcia Campillo Navarro,* Jorge Barrios Payán," Brenda Marquina Castillo, ${ }^{\ddagger}$ Dulce Mata Espinosa, Rogelio Hernández Pando, ${ }^{\ddagger}$ Leslie Chávez Galán*

*INER Ismael Cosío Villegas; INCMN Salvador Zubirán

Introducción: La tuberculosis (TB) es causada por Mycobacterium tuberculosis $(M t b)$. Mtb ingresa al hospedero vía respiratoria, donde en alvéolos pulmonares interacciona con células del sistema inmune, como macrófagos. Durante la infección sistémica murina con BCG hay acumulación de macrófagos que expresan CD3(MO-CD3+) y pueden coexpresan o no el receptor de células T (TCR+/TCR-, respectivamente), sugiriendo que esta subpoblación favorece el proceso inflamatorio durante la infección. Además, en pacientes con TB hay MO-CD3+en la zona epiteloide de granulomas. Actualmente, se desconoce si esta subpoblación es reclutada en fases tempranas de la infección. Objetivo: Evaluar la cinética de migración de MO-CD3+en pulmón durante la TB pulmonar progresiva murina. Hipótesis: Los MO-CD3+ son reclutados durante la etapa temprana de la TB y favorecen la presencia de lesiones pulmonares. Metodología: Ratones BALB/c fueron infectados con la cepa $M t b-H 37 R v$ y sacrificados al 1, 3, 7, 14, 21, 28 día postinfección (dpi). Las células de pulmón fueron caracterizadas fenotípicamente mediante citometría de flujo (CD2, CD3, TCR $\beta$, CD11b, F4/80, MHCII, Gr1). Resultados: En respuesta a la infección, el número total de células pulmonares incrementó $50 \%$ a partir del 7dpi y $10-15 \%$ de células pulmonares fueron macrófagos(CD2-F4/80+MHCII+). A1 1, 3 y 7 dpi hubo 5-7\% de MO-CD3+, similar al ratón no infectado, mientras que al 14 dpi los MO-CD3+ incrementaron del 70-80\% y $40 \%$ de MO-CD3+ expresaron TCR+. Además, se detectó un aumento de neutrófilosCD3+ al 28 dpi. Finalmente, se identificó que MO-CD3+ coexpresaron MHC-II, indicando su importancia para presentación de antígenos en el sitio de infección. Conclusión: Los MO-CD3+TCR-y/o $\mathrm{CD} 3+\mathrm{TCR}+$ son reclutados en pulmón de ratones con TB pulmonar progresiva en la etapa temprana de la infección (14 dpi) y expresan MHC-II. Estos datos sugieren que los MO-CD3+ son relevantes para iniciar la respuesta inmune a TB y podrían favorecer la formación de granulomas y controlar la infección.

\section{Identificación de posibles sustratos para la metaloproteasa de matriz 28}

Mariel Sofía Maldonado-Bonilla, ${ }^{*}$ Jorge Jair García-Álvarez, ${ }^{\ddagger}$ José Guadalupe Cisneros-Lira, ${ }^{\ddagger}$ Martha Montaño-Ramírez ${ }^{\ddagger}$

\section{*INER Ismael Cosío Villegas; ;UNAM}

Introducción: La fibrosis pulmonar idiopática (FPI) es una enfermedad irreversible y frecuentemente letal en la que se sobreexpresan algunas proteínas de la familia de las metaloproteasas de matriz (MMPs). Dentro de ellas se encuentra MMP28, de la cual se desconocen sustratos fisiológicos fuera del sistema nervioso. En la enfermedad, MMP28 se sobreexpresa en células epiteliales a quienes les induce un fenotipo proliferativo y migratorio; además, esta enzima confiere resistencia al proceso de apoptosis. Hipótesis: La sobreexpresión de MMP28 tiene efectos en diversos sustratos que favorecen la supervivencia y migración celular. Objetivo: Estudiar la expresión de proteínas del proceso de apoptosis, así como de proteasas e inhibidores de proteasas en células de epitelio alveolar con el fin de proponer cómo la metaloproteasa de matriz 28 favorece el fenotipo migratorio y la supervivencia. Material y método: Se extrajo proteína de células de epitelio alveolar transfectadas con MMP28 silvestre o MMP28 catalíticamente inactiva (EA) en condiciones control o después de inducir apoptosis con bleomicina para su análisis mediante arreglos de proteínas de componentes de las vías apoptóticas, proteasas e inhibidores de proteasas. Resultados: Los resultados sugieren que en las células que sobreexpresan MMP28 inactiva (EA), el estímulo de bleomicina induce apoptosis como está reportado; sin embargo, en las que sobreexpresan la enzima silvestre, el estímulo induce senescencia. Por otra parte, los otros arreglos sugieren que MMP28 podría degradar ADAMTS1, ADAM9, MMP2, por proteín convertasa 9, calicreína 10 y TIMP4, entre otros. Conclusiones: Con este trabajo se identificaron algunos posibles sustratos directos o indirectos de MMP28, habrá que corroborarlos mediante western blot.

\section{Características clínico-funcionales de las cohortes de linfangioleiomiomatosis de dos centros de referencia de México}

Naomi Yamile Martínez Rodríguez,* Luz Audina Mendoza Topete, ${ }^{\ddagger}$

Felipe de Jesús Contreras Rodríguez, José Omar Barreto Rodríguez,\$

Mayra Edith Mejía Ávila, ${ }^{\S}$ Ivette Buendía Roldán ${ }^{\S}$

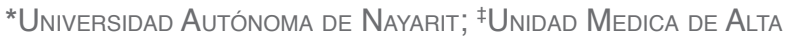
ESPECIALIDAD, CMN dE OCCIDENTE, IMSS; §INER ISMAEL Cosío VILLEGAS 
Linfangioleiomiomatosis (LAM), enfermedad multisistémica caracterizada por crecimiento anormal de músculo liso en parénquima, presentada principalmente en mujeres, asociada o no a esclerosis tuberosa. Nuestro objetivo es describir características clínico-funcionales de LAM en dos centros de referencia en México. Métodos y materiales: Estudio transversal, observacional, descriptivo. Evaluamos dos cohortes retrospectivas período 1997-2019 con revisión de expedientes del INER y Centro Médico de Occidente IMSS Guadalajara. Las variables se analizaron mediante frecuencias y medias con desviaciones estándar. Hipótesis: Existirán diferencias clínicas y bioquímicas en los pacientes con LAM del INER y Centro Médico de Occidente IMSS. Resultados: Estudiamos 18 pacientes, edad $38 \pm 12$ años; $50 \%$ presentó embarazo previo, síntomas iniciales: disnea (89\%), tos (83\%), cianosis (28\%), dolor pleural (39\%); además neumotórax (67\%), quilotórax (33\%), angiomiolipomas (33\%) y esclerosis tuberosa (28\%). En espirometría presentaron patrón obstructivo: relación FEV1/FVC $65 \pm 29$, FEV1 $40 \pm 34 \%$ y FVC $64 \pm 34 \%$, solamente cuatro pacientes tuvieron DLCO $39 \pm 23 \%$, en tres casos caminata de 6 minutos con caída del 11\% aproximadamente. El diagnóstico de LAM $94 \%$ fue con tomografía y $28 \%$ mediante biopsia. El tratamiento farmacológico más utilizado fue sirolimus $56 \%$, seguido por tamoxifeno $17 \%$; tratamiento quirúrgico más utilizado fue sello pleural $50 \%$, toracocentesis $33 \%$, ooforectomía $17 \%$ y pleurodesis $17 \%$. El $61 \%$ de los pacientes utilizaron tratamiento combinado (quirúrgico-farmacológico), 11\% sólo quirúrgico, 11\% sólo farmacológico y $17 \%$ sin tratamiento. Conclusiones: LAM es una enfermedad con baja prevalencia; se corrobora la asociación con estrógeno, disnea como síntoma más frecuente y, en general, sin diferencias entre las cohortes y lo reportado en literatura. LAM sigue siendo una enfermedad con grandes incógnitas que se resolverán al realizar un seguimiento a los pacientes y continuar con investigaciones futuras.

\section{Neumopatías intersticiales no clasificables (NINC): estudio retrospectivo de una cohorte de pacientes mexicanos}

Feymi Areli Gutiérrez-López, ${ }^{*}$ Ana Karem Saucedo-Pruneda, ${ }^{\ddagger}$ Miguel Gaxiola-Gaxiola, ${ }^{\S}$ Ivette Buendía-Roldán ${ }^{\S}$

*Universidad Michoacana de San Nicolás de Hidalgo; :UNAM; §INER ISMAEL Cosío VILLEGaS

Introducción: Las NINC son un subgrupo de las neumopatías intersticiales idiopáticas propuesto por la ATS/ERS en 2002. Se describen como aquellas entidades que no pueden ser categorizadas, incluso después de una discusión multidisciplinaria. La prevalencia reportada es del 10 al 25\%, hasta el 59\% y la mortalidad del $31 \%$. Actualmente, no se cuenta con estudios de pacientes con NINC en México. Hipótesis: Las características y el comportamiento de las NINC son similares a las reportadas en otros países. Objetivo: Describir las características sociodemográficas, clínicas e histopatológicas, así como las pruebas de laboratorio y la terapéutica instaurada de los pacientes con NINC en una cohorte mexicana. Metodología: Estudio retrospectivo, observacional, transversal, de una cohorte de pacientes con diagnóstico de NINC por medio de análisis multidisciplinario en el INER de 2014 a 2019. Resultados: Estudiamos 42 pacientes que presentaron: edad $64+/-9.6$ años, mujeres $52 \%(\mathrm{n}=22)$, IMC $28.3+/-5.34 \mathrm{~kg} / \mathrm{m}^{2}$, antecedente de exposición $71 \%(\mathrm{n}=30)$, siendo la más frecuente a aves, antecedente de tabaquismo 55\% ( $\mathrm{n}=23)$, PFR con FVC 69\% +/- 27, DLCO $54 \%+/-25$, PSAP $33.10+/-10.10$. Perfil reumatológico $60 \%$ fue positivo siendo el más frecuente el factor reumatoide. En el reporte histopatológico se observó un grado de lesión moderado-severo. El LBA no presentó alteraciones celulares. El esquema terapéutico más utilizado fue ácido micofenólico+prednisona $(29 \%, \mathrm{n}=12)$, seguido de prednisona+azatioprina $(19 \%, \mathrm{n}=8)$, sólo en cuatro casos $(9 \%)$ se reportó el uso de pirfenidona. Conclusión: Con base en lo reportado, nuestra cohorte es similar en: edad, género femenino, CVF, DLCO. Con respecto a las especificidades del perfil reumatológico, no se pudo conformar un diagnóstico, lo que corrobora el diagnóstico de NINC. En cuanto al tratamiento, no existen recomendaciones y en nuestra experiencia está pendiente determinar la eficacia de los esquemas utilizados en nuestra cohorte.

\section{Identificación de biomarcadores de autofagia en el pulmón de pacientes con neumonitis por hipersensibilidad}

\author{
Sandra Cabrera-Benítez, ${ }^{*}$ Carolina Rodríguez-Bobadilla, ${ }^{*}$ \\ Pamela Gutiérrez-Chávez,* Miguel Gaxiola-Gaxiola, ${ }^{*}$ \\ Moisés Selman-Lama, ${ }^{\neq}$Annie Pardo-Cemo* \\ *Facultad de Ciencias; ‡INER Ismael Cosío Villegas
}

Introducción: La neumonitis por hipersensibilidad (NH) es un síndrome complejo causado por la exposición a una amplia variedad de partículas orgánicas. En individuos susceptibles, estos antígenos provocan una respuesta inmune exagerada; sin embargo, el papel de la autofagia no ha sido estudiado en la patogénesis de esta enfermedad. La autofagia desempeña funciones críticas en la inflamación, regulando la homeostasis y la supervivencia de las células inflamatorias, así como la secreción de proteínas proinflamatorias. En este estudio evaluamos la expresión de diversas proteínas que participan en la autofagia en tejidos de pacientes con NH. Materiales y métodos: Se utilizó tejido de biopsias de 10 pacientes diagnosticados con $\mathrm{NH}$ y tres individuos control. Para desarrollar la inmunohistoquímica, los cortes de pulmón se incubaron con anticuerpos primarios específicos: antiLC3B, anti-Atg4B, anti-Atg5 y anti-Atg7, seguido de anticuerpo secundario biotinilado, estreptavidina conjugada con peroxidasa y 3-amino-9-etil-carbazol en $\mathrm{H} 2 \mathrm{O} 2$ al $0.05 \%$ como sustrato. Los tejidos fueron contrateñidos con hematoxilina. Resultados: Los tejidos de pulmón de pacientes con $\mathrm{NH}$ mostraron una gran reactividad de los biomarcadores de autofagia LC3B, Atg4B, Atg5, y Atg7 en comparación con el tejido de pulmón sano, y las células positivas fueron esencialmente las células epiteliales alveolares y bronquiales, macrófagos, neutrófilos y macrófagos espumosos. Observamos un citoplasma muy reactivo para las proteínas LC3B, Atg4B, Atg5, y Atg7 en las células del epitelio alveolar con características metaplásicas adyacentes a focos de fibroblastos y en células del epitelio bronquial. Respecto a los macrófagos observamos un patrón punteado para la proteína LC3B, lo que podría estar asociada a autofagosomas en el citoplasma de estos macrófagos. Conclusiones: El papel de la autofagia en NH no ha sido estudiado previamente y nuestros hallazgos indican que podría estar participando activamente en la activación de células epiteliales frente al daño y regular la homeostasis de los macrófagos. 


\section{Papel de M. tuberculosis en la producción de lípidos del circuito inflamatorio en macrófagos infectados}

\author{
Andy Dorey Ruiz-Huerta, ${ }^{*}$ Martha Torres-Rojas, \\ Esmeralda Juárez-Carvajal ${ }^{*}$ \\ *UNAM; ;INER ISMAel Cosío Villegas
}

Mantener el equilibrio inflamatorio es importante en la infección por Mycobacterium tuberculosis. Los macrófagos y neutrófilos son responsables así del inicio como de la resolución de la inflamación mediante la producción de lípidos bioactivos, como prostaglandinas, leucotrienos, lipoxinas, resolvinas y maresinas. Recientemente encontramos que la resolvina D1 (RvD1) y la maresina 1 (Mar1), que derivan del ácido docosahexaenoico (DHA), disminuyen la inflamación por regulación de TNF-a, e inducen péptidos antimicrobianos, ayudando al control microbiológico durante la infección por $M$. tuberculosis cuando son administradas de manera exógena. Debido a que las respuestas inmunes dependientes de RvD1 y Marl no se observan en macrófagos infectados no tratados, suponemos que $M$. tuberculosis interfiere con su síntesis. Para investigar este fenómeno cultivamos MDMs humanos obtenidos de sujetos sanos donadores al banco de sangre del INER con DHA en presencia o ausencia de infección con $M t b$ H37Rv y determinamos la producción de RvD1 y Marl por ELISA. Determinamos la expresión génica de las lipooxigenasas involucradas en la síntesis de RvD1 y Mar1 (5-LOX, 12-LOX, 15-LOX) y la ciclooxigenasa 2 (COX-2) por PCR en tiempo real. Incluimos aspirina como control de la producción de RvD1 y Mar1. Encontramos que el DHA indujo la producción media de RvD1 (4774 pg/mL, rango 4152-4870) y Mar1 (495 pg/mL, rango 350-501) en macrófagos no infectados. La infección con $M t b$ impidió la producción dependiente de DHA de RvD1 (1866 pg/mL, rango 845-2949) y de Mar1 (157 pg/mL, rango 93-173). La adición de aspirina no modificó el efecto de la infección en la producción de lípidos. La infección por M. tuberculosis H37Rv desregula la expresión de 12-LOX y 15-LOX, y modifica los patrones de expresión de 5-LOX y COX2. Concluimos que la infección con $M$. tuberculosis interfiere en el metabolismo del DHA en el macrófago humano para producir resolvinas y maresinas.

\section{Desarrollo de fibrosis pulmonar severa en el ratón doble deficiente de las enzimas MMP8 y MMP13}

\author{
Ángeles García Vicente,* Pamela Gutiérrez Chávez,* \\ Miguel Gaxiola Gaxiola, ${ }^{\ddagger}$ Moisés Selman Lama, ${ }^{\ddagger}$ \\ Annie Pardo Cemo,* Sandra Cabrera Benítez* \\ *Facultad de Ciencias; 抽ER Ismael Cosío Villegas
}

Introducción: Las enzimas MMPs se han implicado en la patogénesis de la fibrosis pulmonar idiopática (FPI), de acuerdo a estudios clínicos que reportan niveles elevados de MMP1, MMP7, MMP8, MMP9 y MMP13 en muestras de sangre, lavado bronquioalveolar (LBA) y/o pulmón. La expresión de MMP8 y MMP13 se ha asociado con fenotipos contradictorios sobre la respuesta inflamatoria y fibrótica, después de una lesión pulmonar y su papel durante la resolución de la fibrosis pulmonar aún no está definido. Objetivo: Evaluar la progresión y resolución de la fibrosis pulmonar en un ratón mutante doble deficiente de las enzimas MMP8 y MMP13. Materiales y métodos: Ratones macho de ocho a 10 semanas fueron tratados con bleomicina y sacrificados a los 7, 28 y 56 días postratamiento. Se evaluó la histología, así como la expresión de distintos marcadores profibrosantes. Por inmunohistoquímica se identificó a la proteína alfa actina de músculo liso en pulmón y por western blot se cuantificó la expresión de colágena, TIMP1, MMP2 y MMP9 en pulmón y LBA. Resultados: Los ratones doble deficientes Mmp8-Mmp13 exhibieron inflamación más extensa a los siete días después del tratamiento con bleomicina y se caracterizó por una mayor infiltración de macrófagos y experimentaron una fibrosis pulmonar más severa y prolongada en comparación con los ratones WT a los 56 días postratamiento. La resolución retardada de la fibrosis, los ratones doble mutantes se distinguió por la presencia de focos fibróticos persistentes y un mayor número de células positivas para alfa actina de músculo liso, un marcador de miofibroblastos. Conclusiones: Nuestros hallazgos indican las enzimas MMP8 y MMP13 juegan un papel antifibrótico y su actividad es crucial durante la reparación pulmonar y la restauración de la integridad del tejido. 